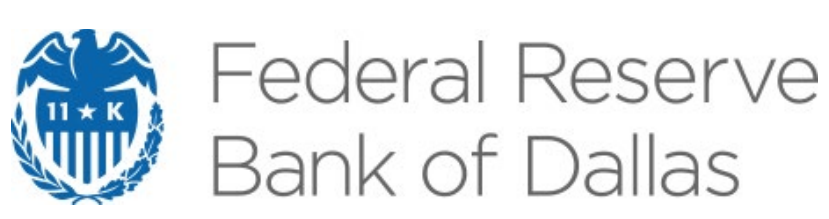

\title{
Nonlinear Search and Matching Explained
}

\author{
Joshua Bernstein, Alexander W. Richter and \\ Nathaniel Throckmorton
}

\section{Working Paper 2106}

Research Department

https://doi.org/10.24149/wp2106

Working papers from the Federal Reserve Bank of Dallas are preliminary drafts circulated for professional comment. The views in this paper are those of the authors and do not necessarily reflect the views of the Federal Reserve Bank of Dallas or the Federal Reserve System. Any errors or omissions are the responsibility of the authors. 


\title{
Nonlinear Search and Matching Explained ${ }^{*}$
}

\author{
Joshua Bernstein ${ }^{\dagger}$, Alexander W. Richter ${ }^{\ddagger}$ and Nathaniel A. Throckmorton ${ }^{\S}$
}

April 27, 2021

\begin{abstract}
Competing explanations for the sources of nonlinearity in search and matching models indicate that they are not fully understood. This paper derives an analytical solution to a textbook model that highlights the mechanisms that generate nonlinearity and quantifies their contributions. Procyclical variation in the matching elasticity creates nonlinearity in the job finding rate, which interacts with the law of motion for unemployment. These results show the matching function choice is not innocuous. Quantitatively, the Den Haan et al. (2000) matching function more than doubles the skewness of unemployment and welfare cost of business cycles, compared to the Cobb-Douglas specification.
\end{abstract}

Keywords: Matching Function; Matching Elasticity; Complementarity; Unemployment

JEL Classifications: E24; E32; E37; J63; J64

\footnotetext{
* This work was supported by computational resources provided by the Big-Tex High Performance Computing Group at the Federal Reserve Bank of Dallas. The views expressed in this paper are our own and do not necessarily reflect the views of the Federal Reserve Bank of Dallas or the Federal Reserve System.

†Joshua Bernstein, Department of Economics, Indiana University, 100 S. Woodlawn, Bloomington, IN 47405, imbernst@iu.edu.

${ }^{\ddagger}$ Alexander W. Richter, Research Department, Federal Reserve Bank of Dallas, 2200 N Pearl Street, Dallas, TX 75201, alex.richter@dal.frb.org.

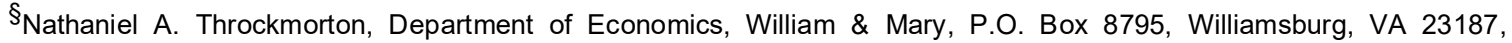
nat@wm.edu.
} 


\section{INTRODUCTION}

Recent work has started to interpret nonlinearities in the data through the lens of the canonical search and matching model à la Diamond-Mortensen-Pissarides (e.g., Abbritti and Fahr, 2013; Dupraz et al., 2019; Ferraro, 2018; Hairault et al., 2010; Petrosky-Nadeau et al., 2018; Pizzinelli et al., 2020). While some papers find large nonlinearities in textbook models, others find smaller effects and rely on additional features to match higher-order moments in the data. These competing explanations indicate that the sources of nonlinearity are not fully understood. This paper derives a closed-form global solution to the search and matching model that sheds light on the mechanisms that generate nonlinearity and then quantifies their contributions in an estimated nonlinear model.

Our analysis reveals a strong link between the choice of the matching function-the mapping from unemployed workers and vacancies into matches - and the amount of nonlinearity. Focusing on the commonly used Cobb-Douglas (CD) and Den Haan et al. (2000, DRW) matching functions, we show the latter specification generates much stronger nonlinearities in labor market dynamics. This finding contrasts with the prevailing view that the matching function choice is innocuous. ${ }^{1}$ The stronger nonlinearities occur because the DRW matching function exhibits gross complementarity between vacancies and unemployed workers and a procyclical matching elasticity-the elasticity of matches with respect to the number of unemployed workers. Gross complementarity implies that the matching elasticity is increasing in labor market tightness, so a larger stock of unemployed workers generates more matches when vacancy creation is high. In contrast, the CD matching function has a constant matching elasticity and is a much weaker source of nonlinearity.

We show the matching elasticity determines the slope of the mapping from productivity shocks to the job finding rate. Under the CD specification, the constant elasticity implies that the job finding rate is approximately linear in productivity, with the slope declining in the size of the elasticity. Intuitively, when the matching elasticity is higher, unemployed workers are relatively more important than vacancies in the matching process. Since only vacancies respond on impact to changes in productivity, a higher matching elasticity weakens the transmission of productivity shocks to the job finding rate. In contrast, the procyclical variation in the matching elasticity generated by the DRW matching function implies that the job finding rate is a concave function of productivity. When productivity is high, the matching elasticity is high and vacancies are relatively less important in the creation of new matches. As a result, the transmission of productivity shocks to the job finding rate is weaker than when productivity is low and vacancies are relatively more important.

Nonlinear job finding rate dynamics driven by gross complementarity interact with unemployment dynamics via its law of motion. While unemployment is inherently a nonlinear stochastic process (Hairault et al., 2010; Jung and Kuester, 2011), we show that nonlinear job finding rate

\footnotetext{
${ }^{1}$ Petrosky-Nadeau and Wasmer (2017) say the two specifications generate similar business cycle moments. The only justification for the DRW matching function is that it restricts the job filling and finding rates to the unit interval.
} 
dynamics exacerbate the state-dependent responses of unemployment to productivity shocks. Intuitively, when productivity is low, a productivity shock causes a stronger response of the job finding rate. If unemployment is high, this leads to a large response of unemployment inflows or outflows.

We assess the quantitative implications of the matching function by estimating our model using a simulated method of moments. Modest procyclical variation in the matching elasticity more than doubles the skewness of unemployment and quadruples the skewness of the job finding rate. In contrast, the model with a constant matching elasticity relies almost entirely on the law of motion for unemployment to generate meaningful nonlinearities. As a result, the welfare cost of business cycles more than doubles, further indicating the power of a procyclical matching elasticity. Finally, the state-dependence from the interaction of the procyclical matching elasticity with the law of motion explains $87 \%$ of the empirical variation in unemployment uncertainty without appealing to exogenous volatility shocks. With a constant matching elasticity, this percentage drops to $39 \%$.

Overall, our results caution against the prevailing view that the matching function choice is innocuous. Small fluctuations in the matching elasticity driven by a departure from the CD specification have significant effects on the nonlinearities. Choosing to use the CD specification places exogenous restrictions on the model's ability to generate nonlinear dynamics. While this naturally creates room for additional mechanisms to explain nonlinearity in the data, it is important to acknowledge that the results depend on the CD matching function. ${ }^{2}$ Likewise, justifying the variation in the matching elasticity implied by the DRW matching function is important to provide credibility to the underlying mechanism. Given the clarity that our results provide on these issues, we hope future empirical work can provide guidance on the amount of time variation in the matching elasticity and the type of matching function that can reconcile these competing explanations in the literature.

Related Literature Our closed-form solution offers a clean way to analyze the sources of nonlinearity in the textbook search and matching model. In important earlier work, Petrosky-Nadeau et al. (2018) numerically analyze the nonlinearities and disaster dynamics in a similar model. They argue that downward rigidity in the marginal cost of vacancy creation is the main driver of the nonlinearities. Our analytical results show the nonlinearities stem from procyclical variation in the matching elasticity created by the DRW matching function and the law of motion for unemployment. While a recent literature uses the DRW specification, these papers do not analyze how this choice influences outcomes other than noting that it restricts the job finding and job filling rates to the unit interval (Ferraro, 2018; Hagedorn and Manovskii, 2008; Hashimzade and Ortigueira, 2005; PetroskyNadeau et al., 2018). ${ }^{3}$ Our analysis emphasizes that the matching function choice is not innocuous.

Previous work examined nonlinearities in the search and matching model under the assump-

\footnotetext{
${ }^{2}$ For example, Dupraz et al. (2019) show their model with a CD matching function cannot generate realistic unemployment dynamics, which helps motivate their focus on downward nominal wage rigidity. In contrast, Petrosky-Nadeau et al. (2018) generate realistic disaster dynamics in a textbook model with a DRW matching function.

${ }^{3}$ Others include Petrosky-Nadeau and Zhang (2017, 2021), Ferraro and Fiori (2020), and Bernstein et al. (2020).
} 
tion of a CD matching function. Hairault et al. (2010) argue that the impact of productivity shocks on the job finding rate is theoretically ambiguous because the job finding rate is a concave function of labor market tightness, which is a convex function of productivity. Using our analytical solution, we show this ambiguity is irrelevant for empirically plausible values of the matching elasticity, which imply almost linear job finding rate dynamics. Relatedly, our quantitative results show almost all nonlinearity stems from the law of motion for unemployment under a CD matching function. Although the skewness of unemployment undershoots the data in this case (Dupraz et al., 2019), it still generates a substantial welfare cost of business cycles, in line with Hairault et al. (2010) and Jung and Kuester (2011). ${ }^{4}$ Importantly, none of these papers consider the effect of relaxing the $\mathrm{CD}$ assumption. We show that allowing for modest procyclical variation in the matching elasticity more than doubles the skewness of unemployment and the associated welfare cost.

Our identification strategy for the structural labor market parameters synthesizes the results of earlier papers. To generate realistic volatilities of unemployment and vacancies, we combine the matching elasticity with the "fundamental surplus," defined as the marginal product of labor minus any resources not allocated to vacancy creation (Ljungqvist and Sargent, 2017). The fundamental surplus sets the overall level of labor market volatility, while the matching elasticity determines how the volatility is split between vacancies and unemployment (Mortensen and Nagypal, 2007). Additionally, we follow Hagedorn and Manovskii (2008) and target the wage elasticity. Relative to this earlier work, we show our strategy allows the model to perfectly match these empirical targets.

Our estimated model is also consistent with recent empirical work that finds macroeconomic uncertainty is often an endogenous response to exogenous first moment shocks rather than an exogenous propagation (Ludvigson et al., 2020). We show a procyclical matching elasticity generates a negatively skewed job finding rate, which is particularly pronounced in deep recessions. The state-dependent transmission of productivity shocks allows the model to match most of the countercyclical variation in macroeconomic uncertainty without relying on exogenous volatility shocks. ${ }^{5}$

The paper proceeds as follows. Section 2 introduces our model. Section 3 derives a closedform solution and discusses the implications of the matching function. Section 4 describes the identification and estimation methods for our structural model. Section 5 shows the quantitative implications of the matching function and law of motion for unemployment. Section 6 concludes.

\section{ENVIRONMENT}

We use a textbook search and matching model similar to Hagedorn and Manovskii (2008). Time is discrete, and the population size (equal to the labor force) is normalized to unity. We consider risk

\footnotetext{
${ }^{4}$ Lepetit (2020) computes welfare costs in a New Keynesian model with labor search and a CD matching function.

${ }^{5}$ From a theoretical perspective, our mechanism complements recent papers that focus on other sources of timevarying endogenous uncertainty (Arellano et al., 2019; Brunnermeier and Sannikov, 2014; Fajgelbaum et al., 2017; Ilut et al., 2018; Mendoza, 2010; Plante et al., 2018; Straub and Ulbricht, 2015; Van Nieuwerburgh and Veldkamp, 2006).
} 
neutral and risk averse households. Under risk aversion, we assume perfect insurance so all households choose the same consumption path (Andolfatto, 1996; Den Haan et al., 2000; Merz, 1995).

Search and Matching Entering period $t$, there are $n_{t-1}$ employed workers and $u_{t-1}=1-n_{t-1}$ unemployed workers. Within the period, a fraction $\bar{s}$ of the employed workers exogenously lose their jobs. The newly separated workers are able to search for new jobs within the same period as their job loss. However, it is natural that these workers will have less time to search for new jobs in period $t$ than those who became unemployed in a previous period. ${ }^{6}$ Therefore, let $\chi \in[0,1]$ denote the fraction of a period that newly separated workers spend searching for work in the same period as their job loss. Then the total number of unemployed searching workers in period $t$ is given by

$$
u_{t}^{s}=u_{t-1}+\chi \bar{s} n_{t-1} .
$$

The matching process is described by a constant returns to scale matching function $\mathcal{M}\left(u_{t}^{s}, v_{t}\right)$, where $v_{t}$ is vacancy postings. ${ }^{7}$ We consider the CD and DRW specifications used in the literature:

$$
\mathcal{M}\left(u_{t}^{s}, v_{t}\right)= \begin{cases}\xi\left(u_{t}^{s}\right)^{\alpha} v_{t}^{1-\alpha} & \mathrm{CD}, \\ u_{t}^{s} v_{t} /\left(\left(u_{t}^{s}\right)^{\iota}+v_{t}^{\iota}\right)^{1 / \iota} & \mathrm{DRW},\end{cases}
$$

where $\xi>0$ denotes matching efficiency and $\alpha \in(0,1)$ and $\iota>0$ govern the relative importance of unemployed searching workers to vacancies in the matching process. Section 3 shows how these parameters map into key elasticities. The number of matches in period $t, m_{t}$, is then defined by

$$
m_{t}=\min \left\{\mathcal{M}\left(u_{t}^{s}, v_{t}\right), u_{t}^{s}, v_{t}\right\}
$$

We can use the matching process to define the job finding and job filling rates,

$$
f_{t}=m_{t} / u_{t}^{s}, \quad q_{t}=m_{t} / v_{t}
$$

where the feasibility condition, (3), ensures $f_{t}, q_{t} \in[0,1]$. The DRW matching function guarantees $m_{t}=\mathcal{M}\left(u_{t}^{s}, v_{t}\right)$, whereas (3) could bind under the CD matching function. When $m_{t}=\mathcal{M}\left(u_{t}^{s}, v_{t}\right)$, we can express the job finding and job filling rates in terms of labor market tightness $\theta_{t} \equiv v_{t} / u_{t}^{s}$,

$$
f_{t}=\left\{\begin{array}{ll}
\xi \theta_{t}^{1-\alpha} & \mathrm{CD}, \\
1 /\left(1+\theta_{t}^{-\iota}\right)^{1 / \iota} & \mathrm{DRW},
\end{array} \quad q_{t}= \begin{cases}\xi \theta_{t}^{-\alpha} & \mathrm{CD}, \\
1 /\left(1+\theta_{t}^{\iota}\right)^{1 / \iota} & \mathrm{DRW}\end{cases}\right.
$$

Following Blanchard and Galí (2010), we assume newly matched workers begin employment in

\footnotetext{
${ }^{6}$ Shimer (2005) makes a similar comment when constructing a measure of the monthly job finding rate in the data.

${ }^{7}$ Pissarides (2000) formalizes the axioms of the matching function and its role in a search and matching model. Petrongolo and Pissarides (2001) survey the empirical evidence for constant returns to scale in the matching function.
} 
the same period they are matched with a firm. Hence, aggregate employment evolves according to

$$
n_{t}=(1-\bar{s}) n_{t-1}+m_{t}
$$

The unemployment rate $u_{t}$ includes anyone who is not employed in period $t$, so it is given by

$$
u_{t} \equiv u_{t}^{s}-m_{t}=1-n_{t}
$$

Firms A firm chooses vacancies and employment $\left\{v_{t}, n_{t}\right\}$ to maximize the present value of dividends, $V_{t}=a_{t} n_{t}-w_{t} n_{t}-\kappa v_{t}+E_{t}\left[x_{t+1} V_{t+1}\right]$, subject to $n_{t}=(1-\bar{s}) n_{t-1}+q_{t} v_{t}$ and $v_{t} \geq 0$, where $\kappa>0$ is the vacancy posting cost, $w_{t}$ is the wage rate, and $E_{t}$ is an expectation operator conditional on time- $t$ information. The pricing kernel, $x_{t+1}=\beta\left(c_{t} / c_{t+1}\right)^{\gamma}$, where $c_{t}$ is consumption, $\beta \in(0,1)$ is the discount factor, and $\gamma \geq 0$ is the coefficient of relative risk aversion. Productivity, $a_{t}$, follows

$$
a_{t+1}=\bar{a}+\rho_{a}\left(a_{t}-\bar{a}\right)+\sigma_{a} \varepsilon_{a, t+1}, 0 \leq \rho_{a}<1, \varepsilon_{a} \sim \mathbb{N}(0,1) .
$$

The optimality conditions imply

$$
\begin{gathered}
\frac{\kappa-\lambda_{v, t}}{q_{t}}=a_{t}-w_{t}+(1-\bar{s}) E_{t}\left[x_{t+1} \frac{\kappa-\lambda_{v, t+1}}{q_{t+1}}\right], \\
\lambda_{v, t} v_{t}=0, \quad \lambda_{v, t} \geq 0,
\end{gathered}
$$

where $\lambda_{v, t}$ is the multiplier on the non-negativity constraint $v_{t} \geq 0$. Condition (8) sets the marginal cost of posting a new vacancy, $\left(\kappa-\lambda_{v, t}\right) / q_{t}$, equal to its marginal benefit, which consists of the flow profits from the match, $a_{t}-w_{t}$, plus the savings from not having to post the vacancy in the future.

Wages We specify a wage rule given by

$$
w_{t}=\eta a_{t}+(1-\eta) b
$$

where $\eta \in(0,1)$ and $b>0$. Following Hall and Milgrom (2008) and Freund and Rendahl (2020), this rule can be derived as the result of an alternating-offers bargaining game in which workers discount future payoffs at rate $\eta$ and receive flow payoff $b$ before a wage agreement is reached. Alternatively, following Jung and Kuester (2011), the wage rule can be derived as maximizing the Nash product $\left(a_{t}-w_{t}\right)^{1-\eta}\left(w_{t}-b\right)^{\eta}$, where $\eta$ is the worker's bargaining power and $b$ is the outside option.

Equilibrium The aggregate resource constraint is given by

$$
c_{t}+\kappa v_{t}=a_{t} n_{t} .
$$

An equilibrium includes sequences of quantities $\left\{c_{t}, n_{t}, u_{t}, u_{t}^{s}, v_{t}, m_{t}, q_{t}, \lambda_{v, t}\right\}_{t=0}^{\infty}$, prices $\left\{w_{t}\right\}_{t=0}^{\infty}$, and productivity $\left\{a_{t}\right\}_{t=1}^{\infty}$ that satisfy (1)-(11) given the initial state $\left\{n_{-1}, a_{-1}\right\}$ and shocks $\left\{\varepsilon_{a, t}\right\}_{t=0}^{\infty}$. 


\section{Analytical Results}

3.1 Solution For tractability, assume risk neutrality. Then combine (8) and (10) to obtain

$$
\frac{\kappa-\lambda_{v, t}}{q_{t}}=(1-\eta)\left(a_{t}-b\right)+\beta(1-\bar{s}) E_{t}\left[\frac{\kappa-\lambda_{v, t+1}}{q_{t+1}}\right] .
$$

We guess and verify that (12) has a solution of the form,

$$
\left(\kappa-\lambda_{v, t}\right) / q_{t}=\delta_{0}+\delta_{1}\left(a_{t}-\bar{a}\right)
$$

where

$$
\delta_{0}=\frac{(1-\eta)(\bar{a}-b)}{1-\beta(1-\bar{s})}, \quad \delta_{1}=\frac{1-\eta}{1-\beta(1-\bar{s}) \rho_{a}}
$$

and $\lambda_{v, t}>0$ only when $q_{t}=1 .^{8}$ The remaining variables can then be solved for recursively as functions of $\left(a_{t}, n_{t-1}\right)$ with (1)-(11). To the best of our knowledge, this solution is new to the literature. ${ }^{9}$

Our solution clarifies the mechanism described in Petrosky-Nadeau and Zhang (2017) and Petrosky-Nadeau et al. (2018), in which the real marginal cost of vacancy creation, $\kappa / q_{t}$, runs into a "downward rigidity". As (13) makes clear, $\kappa / q_{t}$ only faces such a rigidity when productivity falls so low that it causes vacancies to hit the nonnegativity constraint. Since $v_{t}>0$ in the data and almost all simulations, real marginal cost remains linear in productivity and the main source of the nonlinearity must come from elsewhere in the model. Fortunately, we can use our solution to highlight the matching function and law of motion for unemployment as key sources of nonlinearity. ${ }^{10}$

3.2 Matching Function Given (13), we can use the matching function to derive the aggregate supply curve for vacancy creation. Assuming $v_{t}>0$ and $\lambda_{v, t}=0$ for tractability, we obtain

$$
\kappa / q_{t}= \begin{cases}(\kappa / \xi) \theta_{t}^{\alpha} & \mathrm{CD}, \\ \kappa\left(1+\theta_{t}^{\iota}\right)^{1 / \iota} & \mathrm{DRW}\end{cases}
$$

where $v_{t}=\theta_{t} u_{t}^{s}$ implies that vacancies inherit the properties of labor market tightness since $u_{t}^{s}$ is pre-determined in period $t$. This expression captures the upward sloping relationship between the marginal cost of vacancy creation and aggregate vacancies. Since $\delta_{1}>0$ in (13), vacancies are increasing in productivity. In equilibrium, higher productivity raises the marginal benefit of vacancy creation, causing firms to post more vacancies. A rise in vacancies increases labor market tightness, $\theta_{t}$, which raises the marginal cost of vacancy creation until it equals the marginal benefit.

\footnotetext{
${ }^{8}$ Note that for $v_{t}$ arbitrarily close to $0, m_{t}=v_{t}$ by (3). By continuity, $\lambda_{v, t}>0$ implies $q_{t}=1$. Therefore, if productivity is low enough that $\delta_{0}+\delta_{1}\left(a_{t}-\bar{a}\right)<\kappa / q_{t}$ for all $q_{t} \in[0,1]$, then $q_{t}=1$ and $\lambda_{v, t}=\kappa-\delta_{0}-\delta_{1}\left(a_{t}-\bar{a}\right)$.

${ }^{9}$ Pissarides (2009) and Petrosky-Nadeau et al. (2018) add a fixed hiring cost so the marginal cost of vacancy creation is $\kappa_{0} / q_{t}+\kappa_{1}$, rather than $\kappa / q_{t}$. Our analytical and numerical results are robust to this alternative specification.

${ }^{10}$ The absence of matching function parameters in (13) follows from the linear wage rule. However, Appendix C shows the matching function has little or no effect on the marginal cost of vacancy creation under Nash bargaining.
} 
Inverting (14) yields labor market tightness as a function of marginal cost. Combining this result with the matching function and (13) pins down the job finding rate as a function of productivity,

$$
f_{t}= \begin{cases}\xi^{\frac{1}{\alpha}}\left(\frac{\delta_{0}+\delta_{1}\left(a_{t}-\bar{a}\right)}{\kappa}\right)^{\frac{1-\alpha}{\alpha}} & \mathrm{CD}, \\ \left(1-\left(\frac{\kappa}{\delta_{0}+\delta_{1}\left(a_{t}-\bar{a}\right)}\right)^{\iota}\right)^{1 / \iota} & \text { DRW },\end{cases}
$$

which is increasing in productivity since more vacancies create more matches for a given amount of unemployed searching workers. To interpret the dynamics of $f_{t}$ implied by (15), we use two matching function elasticities: (1) The elasticity of matches with respect to unemployed searching, or the matching elasticity $\left(\epsilon_{m_{t}, u_{t}^{s}}\right)$, and (2) The elasticity of substitution between unemployed searching workers and vacancies $(\sigma)$. The CD matching function features a constant matching elasticity $\left(\epsilon_{m_{t}, u_{t}^{s}}=\alpha\right)$ and a unitary elasticity of substitution $(\sigma=1)$. The DRW matching function features a time-varying matching elasticity $\left(\epsilon_{m_{t}, u_{t}^{s}}=f_{t}^{\iota}\right)$ and gross complementarity $(\sigma=1 /(1+\iota)<1) .{ }^{11}$

Figure 1 plots (15) for different values of $\alpha$ and $\iota$, conditional on the two matching functions having the same steady-state matching elasticities $\left(\bar{\epsilon}_{m, u^{s}}=\alpha=\bar{f}^{\iota}\right)$. The other parameters are set to their estimated values in Section 4.5. The values of $\bar{\epsilon}_{m, u^{s}}$ are all in the range of matching elasticities in the data (Mortensen and Nagypal, 2007; Petrongolo and Pissarides, 2001). To facilitate interpretation, we compute the slope of the job finding rate function in terms of the matching elasticity,

$$
\frac{d f_{t}}{d a_{t}}= \begin{cases}\frac{1-\alpha}{\alpha} \phi_{t}^{C D} & \mathrm{CD} \\ \frac{1-\epsilon_{m_{t}, u_{t}^{s}}}{\epsilon_{m_{t}, u_{t}^{s}}} \phi_{t}^{D R W} & \mathrm{DRW}\end{cases}
$$

where $\phi_{t}^{C D}$ and $\phi_{t}^{D R W}$ combine terms that do not impact the key properties of the job finding rate. ${ }^{12}$

First consider the job finding rates under the CD matching function. While (15) shows the curvature depends on $\alpha$ and its shape is ambiguous a priori (Hairault et al., 2010), Figure 1 shows that for empirically consistent values of $\alpha$, the job finding rate is approximately linear over plausible values of productivity. This finding emphasizes the importance of assessing potential nonlinearities in the correct numerical context. The slope of the job finding rate, (16), is decreasing in $\alpha$. The matching elasticity controls the importance of unemployed searching workers in the production of matches, and hence the determination of $f_{t}$. When $\alpha$ is higher under constant returns to scale, unemployed searching workers are more important, while vacancies are less important. However, only vacancies can respond on impact to changes in productivity, so a higher $\alpha$ weakens the transmission of productivity shocks to matches and the job finding rate. Hence, the $f_{t}$ schedule is flatter.

Now turn to the job finding rates under the DRW matching function. In each case, the job find-

\footnotetext{
${ }^{11}$ Stevens (2007) micro-founds the DRW and more general constant elasticity of substitution matching function.

${ }^{12}$ Specifically, $\phi_{t}^{C D}=\left(\xi f_{t}^{1-2 \alpha}\right)^{1 /(1-\alpha)} \delta_{1} / \kappa$ and $\phi_{t}^{D R W}=f_{t}\left(1-f_{t}^{\iota}\right)^{1 / \iota} \delta_{1} / \kappa$. Given a plausible range for the job finding rate, $f_{t} \in(0.2,0.6)$, setting a realistic value of $\alpha=\bar{f}^{\iota} \approx 0.5$ implies $\phi_{t}^{C D}$ and $\phi_{t}^{D R W}$ are close to constant.
} 

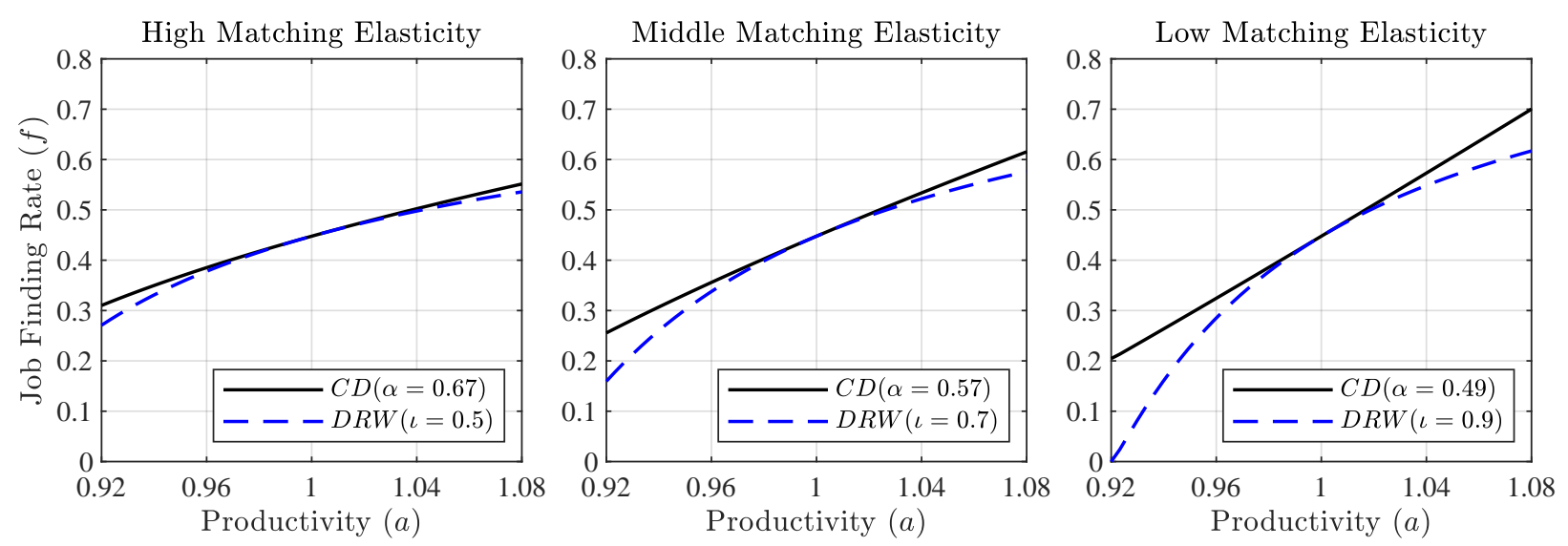

Figure 1: Sensitivity of the job finding rate to changes in productivity.

ing rate lies tangent to its CD counterpart at the steady state level of labor productivity. This property is a result of our calibration and ensures that both matching functions generate the same finding rate $\bar{f}$ and matching elasticity $\bar{\epsilon}_{m, u^{s}}$ when $a_{t}=\bar{a}=1$. Thus, the matching functions generate similar predictions for job finding rate dynamics when productivity fluctuations are sufficiently small.

Crucially, increasing $\iota$ makes the job finding rate more concave by increasing the steepness of the policy function at low productivities relative to high productivities. As a result, the deviations between the CD and DRW job finding rates are increasing in $\iota$, especially at low productivities. We can see this analytically in (16) by noting that the DRW slope term, $\left(1-\epsilon_{m_{t}, u_{t}^{s}}\right) / \epsilon_{m_{t}, u_{t}^{s}}=\left(1-f_{t}^{\iota}\right) / f_{t}^{\iota}$ is time-varying, in contrast with the CD case. Since the matching elasticity is increasing in $f_{t}$, the slope coefficient is decreasing in $f_{t}$. Therefore, the job finding rate is more sensitive to productivity shocks when $f_{t}$ is low. Intuitively, when $f_{t}$ and $\epsilon_{m_{t}, u_{t}^{s}}$ are low, vacancies are important in the production of matches, which amplifies the transmission of productivity shocks to the job finding rate.

To understand why the matching elasticity is procyclical under the DRW matching function, recall that unemployed searching workers and vacancies are gross complements in the production of matches. Therefore, a larger stock of unemployed searching workers generates more matches when vacancy creation is high and the labor market is tight. This is captured by the matching elasticity $\epsilon_{m_{t}, u_{t}^{s}}=f_{t}^{\iota}$, which is increasing in labor market tightness. It is also useful to note that relatively little time-variation in the matching elasticity is necessary to generate significant nonlinearities in the job finding rate. For example, when $\bar{\epsilon}_{m, u^{s}}=0.5,\left(1-\epsilon_{m_{t}, u_{t}^{s}}\right) / \epsilon_{m_{t}, u_{t}^{s}}=-4$ in the neighborhood of steady state, so a $\pm 5 \%$ change in $\epsilon_{m_{t}, u_{t}^{s}}$ causes a $\pm 20 \%$ change in the slope of the job finding rate.

3.3 Unemployment DynAmics The specification of the matching function also has important consequences for unemployment dynamics. The law of motion for unemployment is given by

$$
u_{t}=u_{t-1}+\bar{s}\left(1-u_{t-1}\right)-f_{t} u_{t}^{s}
$$


Under the CD and DRW matching functions, the interaction between the job finding rate and unemployed searching workers captured by $f_{t} u_{t}^{s}$ is a source of state-dependence. When $u_{t}^{s}$ is higher, labor productivity shocks have a larger impact on unemployment. Intuitively, any change in the job finding rate has a larger effect on unemployment when it is applied to a larger pool of workers.

Since $u_{t}^{s}$ is pre-determined, $d u_{t} / d a_{t}=-u_{t}^{s} d f_{t} / d a_{t}$, so the unemployment response to productivity shocks inherits the properties of the job finding rate response. Under the DRW matching function, unemployment responds more to shocks during recessionary periods when the job finding rate is already low, creating additional state-dependence that is absent under the CD specification.

The state-dependence is summarized by the variation in uncertainty. Following Jurado et al. (2015), we define uncertainty as the conditional volatility of the forecast error for unemployment,

$$
\mathcal{U}_{t, t+1}^{u}=\sqrt{E_{t}\left[\left(u_{t+1}-E_{t} u_{t+1}\right)^{2}\right]}=u_{t+1}^{s} \sqrt{V_{t}\left[f_{t+1}\right]}
$$

where $V_{t}$ denotes conditional variance. There are two endogenous sources of variation in unemployment uncertainty. First, the unemployment forecast error depends on the number of unemployed searching workers. When $u_{t+1}^{s}$ is higher, the variation in the job finding rate $f_{t+1}$ is amplified, creating more uncertainty about $u_{t+1}$ in period $t$. Second, when the job finding rate is a nonlinear function of productivity, its conditional variance is also state-dependent. For example, under the DRW matching function, $f_{t}$ is concave in $a_{t}$, and the variance of $f_{t+1}$ is higher when productivity is lower. Intuitively, lower $a_{t}$ shifts the distribution of future productivity to the steeper portion of the job finding rate schedule, resulting in greater variability and higher unemployment uncertainty.

\section{Model IdentificATION AND Estimation}

4.1 Data Sources We use data from 1955-2019. Following Shimer (2005), the job finding rate is $f_{t} \equiv 1-\left(U_{t+1}-U_{t+1}^{s}\right) / U_{t}$, where $U_{t}$ is total unemployed and $U_{t}^{s}$ is the subset who are unemployed one month or less in the Current Population Survey. The unemployment rate is $u_{t}=U_{t} / L F_{t}$, where $L F_{t}$ is the labor force. The vacancy rate $v_{t}$ is based on the series in Barnichon (2010) until 2000, after which it equals job openings as a share of the labor force from the Job Openings and Labor Turnover Survey. These series correct for trends in the print and online help-wanted indexes published by the Conference Board. Labor productivity is measured by the series for the non-farm business sector from the Bureau of Labor Statistics. Following Hagedorn and Manovskii (2008), the wage rate is the product of labor productivity and the labor share in the non-farm business sector. We aggregate the monthly labor market series to a quarterly frequency so they match the frequency of labor productivity and wages. Appendix A provides more information.

4.2 IDENTIFICATION This section explains our identification scheme. For simplicity, we conduct our analysis in the deterministic steady state, but the intuition holds nonlinearly. The disagree- 
ment payoff $b$ governs the economy's "fundamental surplus fraction" (Ljungqvist and Sargent, 2017), defined as the upper bound on the fraction of a worker's output that can be allocated to vacancy creation. A small fundamental surplus fraction is crucial to deliver realistic volatilities of unemployment and vacancies (Hagedorn and Manovskii, 2008; Ljungqvist and Sargent, 2017). To see this, combine the vacancy creation condition, (8), with the wage rule, (10), in steady state to obtain

$$
\kappa / \bar{q}=(1-\eta)(\bar{a}-b) /(1-\beta(1-\bar{s}))
$$

Differentiating then yields an expression for the elasticity of tightness with respect to productivity,

$$
\bar{\epsilon}_{\theta, a}=\frac{\bar{a}}{\bar{a}-b} \times \frac{1}{\bar{\epsilon}_{m, u^{s}}},
$$

where $(\bar{a}-b) / \bar{a}$ is the fundamental surplus fraction and $\bar{\epsilon}_{m, u^{s}}$ is the steady-state elasticity of matches with respect to unemployed searching. Given estimates for $\bar{\epsilon}_{m, u^{s}}$ typically range from 0.3-0.7 (Mortensen and Nagypal, 2007; Petrongolo and Pissarides, 2001), a large response of labor market tightness to changes in labor productivity requires a small fundamental surplus fraction, which requires that $b$ is close to the marginal product of labor, $\bar{a}$. A small fundamental surplus fraction makes labor market tightness, and hence unemployment and vacancies, sensitive to changes in labor productivity. Therefore, we identify $b$ by targeting the two standard deviations in the data.

While $b$ changes the volatilities of unemployment and vacancies, $\bar{\epsilon}_{m, u^{s}}$ affects their relative volatilities. Consider the elasticities of unemployment and vacancies with respect to tightness: ${ }^{13}$

$$
\begin{gathered}
\bar{\epsilon}_{u, \theta}=-(1-\bar{u})\left(1-\bar{\epsilon}_{m, u^{s}}\right) /(1-\chi \bar{f}), \\
\bar{\epsilon}_{v, \theta}=1-\left(1-\chi \bar{s} / \bar{u}^{s}\right)(1-\bar{u})\left(1-\bar{\epsilon}_{m, u^{s}}\right) /(1-\chi \bar{f}) .
\end{gathered}
$$

As $\bar{\epsilon}_{m, u^{s}}$ increases, the responsiveness of unemployment to changes in labor market tightness shrinks relative to the responsiveness of vacancies. Intuitively, when $\bar{\epsilon}_{m, u^{s}}$ is higher, an increase in matches requires a smaller increase in unemployed searching, and hence in unemployment. Therefore, when matches fluctuate, unemployment fluctuates less relative to vacancies. Hence, we identify $\bar{\epsilon}_{m, u^{s}}$ by targeting the relative standard deviations of unemployment and vacancies in the data.

We partially identify the matching function by fixing $\bar{\epsilon}_{m, u^{s}}$ across the two matching functions:

$$
\bar{\epsilon}_{m, u^{s}}=\alpha=\bar{f}^{\iota}
$$

Identifying $\bar{\epsilon}_{m, u^{s}}$ is equivalent to identifying $\alpha$ in the CD matching function. Furthermore, given that we set $\bar{f}$ to target the average job finding rate in the data, we can pin down $\iota$ in the DRW matching function. Setting $\bar{f}$ also pins down the steady-state DRW job filling rate, $\bar{q}=\left(1-\bar{f}^{\iota}\right)^{1 / \iota}$.

\footnotetext{
${ }^{13}$ The elasticities come from differentiating the steady-state conditions $\bar{u}=\bar{s}(1-\chi \bar{f}) /(\bar{s}(1-\chi \bar{f})+\bar{f})$ and $\bar{v}=\bar{\theta} \bar{u}^{s}$.
} 
We set the CD matching efficiency so $\bar{q}$ is consistent across the matching functions, which implies

$$
\xi=\bar{q}^{1-\alpha} \bar{f}^{\alpha}
$$

Recall from (10) that $\eta$ governs the responsiveness of the wage rate to changes in the marginal product of labor, which is driven by labor productivity. Hence, we follow Hagedorn and Manovskii (2008) and identify $\eta$ by targeting the elasticity of the wage rate with respect to labor productivity.

We set $\bar{u}$ and $\bar{s}$ to target the average unemployment and job separation rates. We then solve for the vacancy posting cost, $\kappa$, and intra-period search duration, $\chi$, using the steady-state conditions:

$$
\begin{gathered}
\kappa=\bar{q}(1-\eta)(\bar{a}-b) /(1-\beta(1-\bar{s})), \\
\chi=((1-\bar{u}) \bar{s}-\bar{f} \bar{u}) /((1-\bar{u}) \bar{s} \bar{f}) .
\end{gathered}
$$

Steady-state labor productivity, $\bar{a}$, is normalized to unity and the steady-state job separation rate, $\bar{s}$, is set to its sample average. We identify the parameters of the exogenous process, $\left\{\rho_{a}, \sigma_{a}\right\}$, by targeting the quarterly standard deviation and autocorrelation of labor productivity in the data.

4.3 Solution We solve the nonlinear model with the policy function iteration algorithm in Richter et al. (2014), which is based on the theoretical work on monotone operators in Coleman (1991). The algorithm minimizes the Euler equation errors on each node in the discretized state space. It then computes the maximum distance between the policy functions on any node and iterates until it falls below the tolerance criterion. We approximate the productivity process with Gauss-Hermite quadrature and use piecewise linear interpolation to calculate the updated policy functions. Following Garcia and Zangwill (1981), we ensure that $v_{t} \geq 0$ by introducing an auxiliary variable, $\mu_{t}$, that satisfies $v_{t}=\max \left\{0, \mu_{t}\right\}^{2}$ and $\lambda_{v, t}=\max \left\{0,-\mu_{t}\right\}^{2} \cdot \mu_{t}$ maps into vacancies when $v_{t}>0$ and the Lagrange multiplier, $\lambda_{v, t}$, when $v_{t}=0$. See Appendix B for more information.

4.4 Estimation The discount factor, $\beta$, is set to 0.9983 , consistent with an annual real interest rate of $2 \%$, and the coefficient of relative risk aversion, $\gamma$, is set to 1 , consistent with log utility. The empirical targets are stored in $\hat{\Psi}_{T}^{D}$ and estimated with a two-step Generalized Method of Moments (GMM) estimator, where $T=780$ months. Given these values, the parameters are estimated with a Simulated Method of Moments. For parameterization $\mathcal{P}$ and shocks $\mathcal{E}=\left\{\varepsilon_{a}\right\}$, we solve the nonlinear model and simulate it $R=1,000$ times for $T$ months, the same length as our data. The model analogues of the $\Psi_{T}^{D}$ empirical targets are the mean moments across the $R$ simulations, $\bar{\Psi}_{R, T}^{M}(\mathcal{P}, \mathcal{E})$.

The parameter estimates are obtained by minimizing the following quadratic loss function:

$$
J(\mathcal{P}, \mathcal{E})=\left[\hat{\Psi}_{T}^{D}-\bar{\Psi}_{R, T}^{M}(\mathcal{P}, \mathcal{E})\right]^{\prime}\left[\hat{\Sigma}_{T}^{D}(1+1 / R)\right]^{-1}\left[\hat{\Psi}_{T}^{D}-\bar{\Psi}_{R, T}^{M}(\mathcal{P}, \mathcal{E})\right]
$$

where $\hat{\Sigma}_{T}^{D}$ is the diagonal of the GMM estimate of the variance-covariance matrix of the empirical 
targets. The targets are based on quarterly data, in percent deviations from a Hamilton (2018) filtered trend. ${ }^{14}$ Each period in the model is 1 month, so we aggregate the simulated time series to a quarterly frequency. We then detrend the simulated data by computing percent deviations from the time average, so the units of each moment are directly comparable to their counterpart in the data.

\begin{tabular}{lcclcc}
\hline Model Parameter & & Value & Empirical Target & Data & Model \\
\hline Intra-Period Search Duration & $\chi$ & 0.5294 & Average Unemployment Rate & 5.89 & 5.89 \\
Vacancy Posting Cost & $\kappa$ & 0.2100 & Average Job-Finding Rate & 42.14 & 42.14 \\
Job Separation Rate & $\bar{s}$ & 0.0327 & Average Job Separation Rate & 3.27 & 3.27 \\
Disagreement Payoff & $b$ & 0.9337 & Unemployment Standard Deviation & 23.66 & 23.66 \\
Matching Elasticity & $\bar{\epsilon}_{m, u^{s}}$ & 0.5916 & Vacancy Standard Deviation & 21.69 & 21.69 \\
Bargaining Weight & $\eta$ & 0.5723 & Wage-Labor Productivity Elasticity & 0.59 & 0.59 \\
Productivity Persistence & $\rho_{a}$ & 0.9537 & Labor Prod. Autocorrelation & 0.89 & 0.89 \\
Shock Standard Deviation & $\sigma_{a}$ & 0.0083 & Labor Prod. Standard Deviation & 2.61 & 2.61 \\
\hline
\end{tabular}

Table 1: Estimated parameter values under the DRW matching function.

4.5 Estimated Parameters Table 1 reports the parameter estimates under the DRW matching function. The disagreement payoff, $b$, is 0.934 , just below the estimate of 0.955 in Hagedorn and Manovskii (2008). Workers' bargaining power, $\eta$, is 0.572 , similar to Jung and Kuester (2011) who also use a linear wage rule. The steady-state matching elasticity, $\bar{\epsilon}_{m, u^{s}}$, is 0.592 , which is within the $(0.3,0.7)$ range suggested by Petrongolo and Pissarides $(2001)$. Given $\bar{\epsilon}_{m, u^{s}}=\alpha$, the DRW matching curvature is $\iota=\log \alpha / \log \bar{f}=0.645$. The implied elasticity of substitution, $\sigma=1 /(1+\iota)$, is 0.608 , which is well below the unitary elasticity implied by a CD matching function. It is also much higher than the implied elasticity of 0.47 in Petrosky-Nadeau et al. (2018), which would generate considerably larger nonlinearities from the DRW matching function. The steady-state job filling rate is $\bar{q}=\left(1-\bar{f}^{\iota}\right)^{1 / \iota}=0.254$, which lines up with the quarterly calibration in Den Haan et al. (2000). Given that value, the CD matching efficiency is $\xi=\bar{q}^{1-\alpha} \bar{f}^{\alpha}=0.349$.

\section{MACRO IMPLICATIONS}

5.1 Moments Table 2 reports key moments conditional on the parameter estimates in Table 1. To identify the sources of nonlinearity, we compare our estimated model with a DRW matching function to models with a CD matching function and a linear law of motion for unemployment. ${ }^{15}$

Consider first our baseline model (column DRW-1). The targeted moments shown in bold perfectly match their empirical counterparts, indicating the strength of our identification scheme.

\footnotetext{
${ }^{14}$ Specifically, we regress each time series on its most recent 4 lags following an 8 quarter window. Hodrick (2020) shows this approach is more accurate than an HP filter when time series, such as ours, are first-difference stationary.

${ }^{15}$ Appendix E shows our results are robust to estimating the model with the CD matching function instead of DRW.
} 


\begin{tabular}{|c|c|c|c|c|c|c|c|c|}
\hline \multirow[b]{2}{*}{ Moment } & \multirow[b]{2}{*}{ Data } & \multirow[b]{2}{*}{$\mathrm{SE}$} & \multicolumn{2}{|c|}{ DRW } & \multicolumn{2}{|c|}{$\mathrm{CD}$} & \multicolumn{2}{|c|}{ Linear } \\
\hline & & & 1 & 2 & 1 & 2 & 3 & 4 \\
\hline$S D(u)$ & 23.66 & 2.51 & 23.66 & 16.52 & 16.79 & 14.93 & 16.29 & 15.71 \\
\hline$S D(v)$ & 21.69 & 1.51 & 21.69 & 22.78 & 20.83 & 21.11 & 20.00 & 20.68 \\
\hline$S D(f)$ & 14.96 & 1.47 & 15.88 & 15.60 & 13.26 & 13.23 & 12.95 & 12.94 \\
\hline $\operatorname{Skew}(u)$ & 1.10 & 0.35 & 1.91 & 0.71 & 0.82 & 0.12 & 0.65 & 0.00 \\
\hline $\operatorname{Skew}(v)$ & -0.02 & 0.35 & -0.19 & -0.31 & -0.01 & -0.17 & 0.24 & 0.00 \\
\hline Skew $(f)$ & -0.60 & 0.45 & -0.80 & -0.73 & -0.16 & -0.13 & -0.02 & 0.00 \\
\hline Slope $(w, a)$ & 0.59 & 0.08 & 0.59 & 0.59 & 0.59 & 0.59 & 0.59 & 0.59 \\
\hline $\operatorname{Corr}(u, v)$ & -0.74 & 0.05 & -0.85 & -0.95 & -0.92 & -0.95 & -0.91 & -0.95 \\
\hline$S D\left(U_{u}\right)$ & 6.49 & 0.59 & 5.62 & 3.89 & 2.52 & 0.79 & 3.16 & 0.00 \\
\hline
\end{tabular}

Table 2: Data and simulated moments. Models: (1) All nonlinear; (2) All nonlinear except linear law of motion; (3) All linear except nonlinear law of motion; (4) All linear. Bolded values indicate targeted moments.

Focusing on nonlinearities, the model generates substantial skewness in unemployment and the job finding rate. As a result, the model also endogenously generates realistic movements in unemployment uncertainty. The standard deviation $S D\left(U_{u}\right)$ equals $87 \%$ of the standard deviation of the real uncertainty index in Ludvigson et al. (2020), without appealing to exogenous volatility shocks. ${ }^{16}$ Importantly, these nonlinearities only require small movements in the matching elasticity, which has a mean of 0.59 and a standard deviation of 0.06 . Thus, fluctuations in the matching elasticity rarely leave the conventional range of values $(0.3,0.7)$ used in the literature (Mortensen and Nagypal, 2007; Petrongolo and Pissarides, 2001). This illustrates the strength of the nonlinear mechanism generated by the procyclical matching elasticity embedded in the DRW matching function. ${ }^{17}$

The term for new matches in the law of motion for unemployment, $m_{t}=f_{t} u_{t}^{s}$, also generates nonlinearity in the model. To isolate the nonlinearity from the matching function, we compare the baseline model to a model with a linear law of motion for unemployment (column DRW-2). The DRW matching function alone generates roughly $37 \%$ of the baseline skewness in unemployment, $91 \%$ of the skewness in the job finding rate, and $69 \%$ of the volatility in unemployment uncertainty. This shows the DRW matching function is essentially the sole source of the skewness in the job finding rate, which then interacts with the law of motion to increase the skewness in unemployment.

We can also isolate the effects of the procyclical matching elasticity by solving the model using a $\mathrm{CD}$ matching function (column $\mathrm{CD}-1$ ). Removing time-variation in the matching elasticity reduces the skewness in unemployment by $57 \%$, the skewness in the job finding rate by $80 \%$, and the volatility in unemployment uncertainty by $55 \%$. In line with our analytical results, the con-

\footnotetext{
${ }^{16}$ We use a quarterly average of the monthly real uncertainty series $(h=1)$ from Ludvigson et al. (2020). This series is a sub-index of the macro uncertainty series from Jurado et al. (2015) that accounts for 73 real activity variables. To make the units from our model comparable to the real uncertainty series, we define $S D\left(\mathcal{U}^{u}\right) \equiv S D\left(\mathcal{U}_{t, t+1}^{u}\right) / S D\left(u_{t}\right)$.

${ }^{17}$ Appendix D shows our qualitative results carry over when we add job separation rate shocks to our baseline model.
} 
stant matching elasticity generates almost linear job finding rate dynamics with little skewness. Crucially, when we then linearize the law of motion for unemployment, there is essentially no skewness in either unemployment of the job finding rate (column CD-2). This holds even though the other equations in the equilibrium system remain nonlinear. This shows almost all of the nonlinearity stems from the law of motion for unemployment when the matching elasticity is constant.

Finally, to further highlight the importance of the law of motion in generating nonlinearities, we compare the moments in a fully linearized model to a model in which we linearize all equations except for the law of motion for unemployment. In the fully linear model, we do not differentiate between the matching functions because they are equivalent. As expected, there is no skewness in unemployment or the job finding rate in this case. Simply introducing a nonlinear law of motion for unemployment generates nearly all of the skewness in unemployment and all of the volatility of unemployment uncertainty that occurs in the fully nonlinear model with a CD matching function.

\subsection{IMPULSE RESPONSES Recall from Figure 1 that the DRW matching function predicts sim-} ilar job finding rate dynamics to the $\mathrm{CD}$ matching function when the economy is near steady state, but larger fluctuations when the economy is in a recession. Figure 2 demonstrates this property by plotting generalized impulse responses of unemployment and the job finding rate to a 2 standard deviation negative labor productivity shock. ${ }^{18}$ We illustrate the state-dependence of the responses by initializing each of the simulations at steady state $\left(u_{0}=5.9 \%\right)$ and a severe recession $\left(u_{0}=10 \%\right)$.

Under the CD matching function, the constant matching elasticity implies that the state of the economy has no discernible impact on the job finding rate response. State-dependency only occurs in the unemployment response, rising from a peak effect of 0.6 percentage points when the economy is in steady state to 1.2 percentage points in a severe recession. When the law of motion for unemployment is linear, there is no state-dependency since it is the only major source of nonlinearity.

In contrast, the procyclical matching elasticity embedded in the DRW matching function generates state-dependency in both responses, even with a linear law of motion for unemployment. Furthermore, the responses when the economy is in a severe recession are larger than under the $\mathrm{CD}$ matching function. In the fully nonlinear model, the job finding rate falls 7.5 percentage points when the unemployment rate is $10 \%$ and only 4.5 percentage points when the economy is in steady state. It also triples the peak unemployment response, rising from 0.7 to 2.3 percentage points. Importantly, the responses in normal times coincide with those under the $\mathrm{CD}$ matching function, indicating that the DRW matching function only alters labor market dynamics in severe recessions.

5.3 Welfare Cost of Business Cycles To further examine the implications of the matching function, we compute the welfare cost of business cycles by implementing the experiment

\footnotetext{
${ }^{18}$ Following Koop et al. (1996), the response of $x_{t+h}$ over horizon $h$ is given by $\mathcal{G}_{t}\left(x_{t+h} \mid \varepsilon_{a, t+1}=-2, \mathbf{z}_{t}\right)=$ $E_{t}\left[x_{t+h} \mid \varepsilon_{a, t+1}=-2, \mathbf{z}_{t}\right]-E_{t}\left[x_{t+h} \mid \mathbf{z}_{t}\right]$, where $\mathbf{z}_{t}$ is a vector of initial states and -2 is the shock size in period $t+1$.
} 

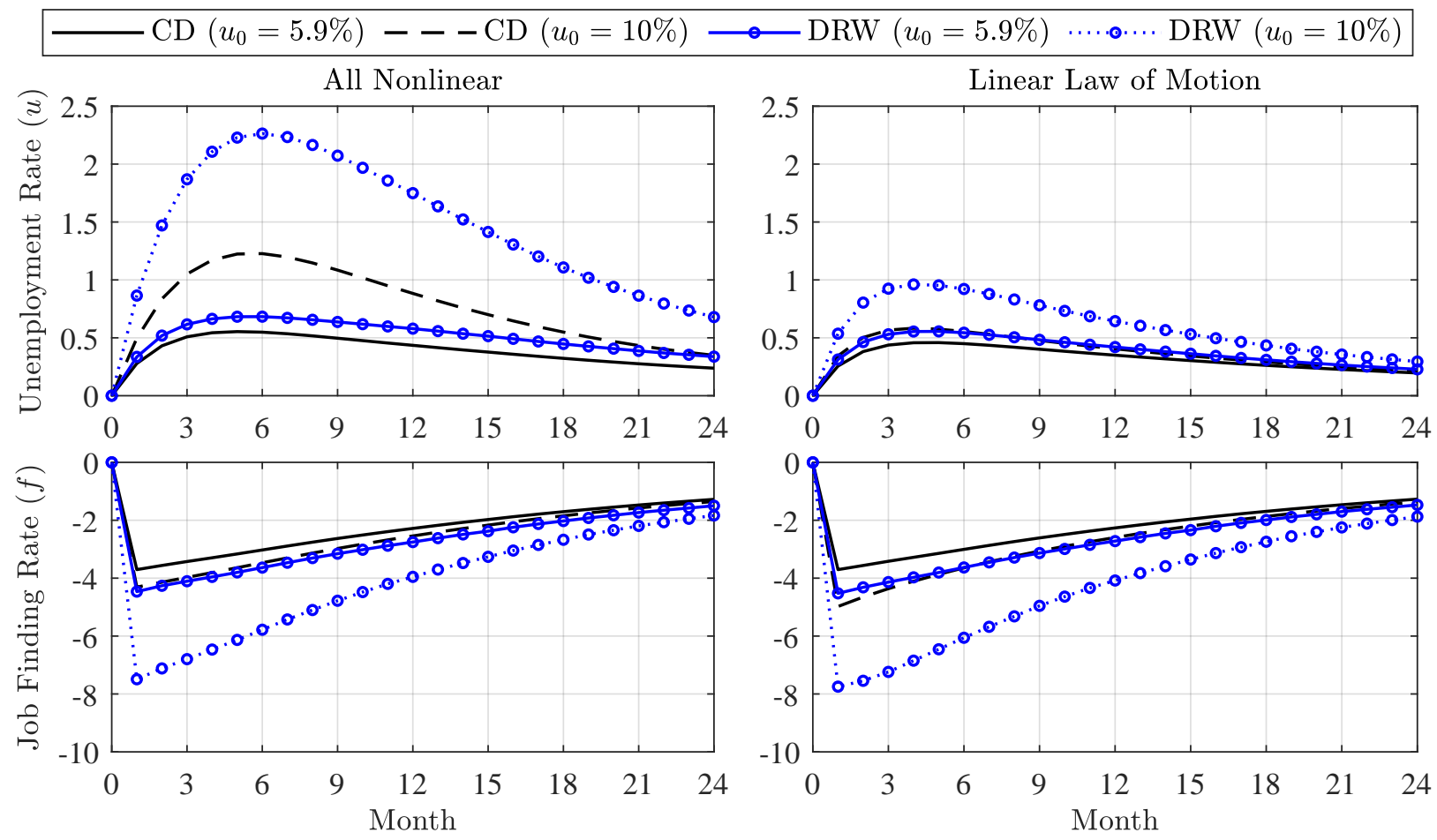

Figure 2: Generalized impulse responses to a negative 2 standard deviation productivity shock.

in Lucas $(1987,2003) .{ }^{19}$ We first compute the representative household's lifetime utility in an economy where consumption always equals its stochastic steady state, $\tilde{c}$. Then we compute expected welfare in the stochastic economy and solve for the percentage of stochastic consumption $\lambda$ households would require to make them indifferent between the two consumption paths. Formally, $\lambda=100 \times\left(\exp \left(\ln \tilde{c}-\frac{1-\beta}{1-\beta^{T-1}} \frac{1}{N_{E}} \sum_{j=1}^{N_{E}} E_{0}\left[\sum_{t=0}^{T} \beta^{t} \ln c_{j, t} \mid \mathbf{z}_{j, 0}\right]\right)-1\right)$, where $T=3000, \mathbf{z}_{j, 0}$ is the $j$ th draw from the ergodic distribution with path $\left\{c_{j, t}\right\}$ and $N_{E}=20,000$ is the number of draws.

With the CD matching function, we find $\lambda=0.18 \%$, so households require an additional $0.18 \%$ of consumption in each period to accept the fluctuations from business cycles. This number is over 4 times larger than the linear model (0.04\%), which is close to the cost reported in Lucas $(2003, \lambda=$ $0.05 \%$ ) when aggregate consumption is a Gaussian process. Under a DRW matching function, the cost of business cycles is $0.43 \%$, more than double the cost with the CD matching function. These results further emphasize the importance of the matching function for characterizing nonlinearities.

\section{CONCLUSION}

Analyzing macroeconomic nonlinearities through the lens of the search and matching model is an exciting and growing area of research. We contribute to this enterprise by analyzing the implications of a key model ingredient: the matching function. Using closed-form analytics and an esti-

\footnotetext{
${ }^{19}$ Appendix F shows the matching function choice also affects the vacancy subsidy that restores economic efficiency.
} 
mated model, we show the matching function choice greatly affects the model's ability to generate nonlinear dynamics, in contrast to the prevailing view that it is innocuous. The matching function is a powerful source of nonlinearity when it features a procyclical matching elasticity. This is the case for the DRW matching function, but not the CD matching function. As a result, a textbook model with the DRW matching function significantly increases the skewness of the unemployment rate and welfare cost of business cycles. In contrast, a model with the CD matching function relies almost entirely on the law of motion for unemployment to generate nonlinearity. We hope future work can use our results to provide guidance on the type of matching function that best fits the data.

\section{REFERENCES}

ABbritTi, M. AND S. FAHR (2013): “Downward wage rigidity and business cycle asymmetries," Journal of Monetary Economics, 60, 871-886, https://doi.org/10.1016/j.jmoneco.2013.08.001.

Andolfatto, D. (1996): "Business Cycles and Labor-Market Search," American Economic Review, 86, 112-132.

Arellano, C., Y. BAI, And P. J. Kehoe (2019): "Financial Frictions and Fluctuations in Volatility," Journal of Political Economy, 127, 2049-2103, https://doi.org/10.1086/701792.

BARNICHON, R. (2010): “Building a composite Help-Wanted Index,” Economics Letters, 109, 175-178, https://doi.org/10.1016/j.econlet.2010.08.029.

Bernstein, J., A. W. Richter, And N. A. Throckmorton (2020): “Cyclical Net Entry and Exit," Federal Reserve Bank of Dallas Working Paper 2018, https://doi.org/10.24149/wp2018r1.

Blanchard, O. And J. Galí (2010): "Labor Markets and Monetary Policy: A New Keynesian Model with Unemployment," American Economic Journal: Macroeconomics, 2, 1-30, https://doi.org/10.1257/mac.2.2.1.

Brunnermeier, M. K. And Y. SAnnikov (2014): “A Macroeconomic Model with a Financial Sector," American Economic Review, 104, 379-421, https://doi.org/10.1257/aer.104.2.379. Coleman, II, W. J. (1991): "Equilibrium in a Production Economy with an Income Tax," Econometrica, 59, 1091-1104, https://doi.org/10.2307/2938175.

Coles, M. G. And A. M. Kelishomi (2018): "Do Job Destruction Shocks Matter in the Theory of Unemployment?” American Economic Journal: Macroeconomics, 10, 118-136, https://doi.org/10.1257/mac.20150040.

Den HaAn, W. J., G. RAMEY, And J. WATSON (2000): “Job Destruction and Propagation of Shocks," American Economic Review, 90, 482-498, https://doi.org/10.1257/aer.90.3.482.

Dupraz, S., E. Nakamura, And J. Steinsson (2019): “A Plucking Model of Business Cycles," NBER Working Paper 26351, https://doi.org/10.3386/w26351. 
Elsby, M. W. L., G. Solon, And R. Michaels (2009): “The Ins and Outs of Cyclical Unemployment," American Economic Journal: Macroeconomics, 1, 84-110, https://doi.org/10.1257/mac.1.1.84.

Fajgelbaum, P., M. Taschereau-Dumouchel, and E. SchaAl (2017): "Uncertainty Traps," The Quarterly Journal of Economics, 132, 1641-1692, https://doi.org/10.1093/qje/qjx02.

FErraro, D. (2018): “The Asymmetric Cyclical Behavior of the U.S. Labor Market,” Review of Economic Dynamics, 30, 145-162, https://doi.org/10.1016/j.red.2018.05.005.

FERRARO, D. AND G. FIORI (2020): “Non-linear employment effects of tax policy,” SSRN Working Paper 3740242, https://dx.doi.org/10.2139/ssrn.3740242.

FREUND, L. AND P. RENDAHL (2020): "Unexpected Effects: Uncertainty, Unemployment, and Inflation," CEPR Discussion Paper 14690.

Garcia, C. B. AND W. I. Zangwill (1981): Pathways to Solutions, Fixed Points and Equilibria, Prentice-Hall series in computational mathematics, Prentice-Hall.

HAgEdorn, M. AND I. MANOvSKII (2008): “The Cyclical Behavior of Equilibrium

Unemployment and Vacancies Revisited," American Economic Review, 98, 1692-1706, https://doi.org/10.1257/aer.98.4.1692.

Hairault, J.-O., F. LANGOt, And S. Osotimehin (2010): "Matching frictions, unemployment dynamics and the cost of business cycles," Review of Economic Dynamics, 13, 759-779, https://doi.org/10.1016/j.red.2010.05.001.

HALL, R. E. AND P. R. MilgRom (2008): “The Limited Influence of Unemployment on the Wage Bargain," American Economic Review, 98, 1653-1674, https://doi.org/10.1257/aer.98.4.1653.

Hamilton, J. D. (2018): “Why You Should Never Use the Hodrick-Prescott Filter," Review of Economics and Statistics, 100, 831-843, https://doi.org/10.1162/rest_a_00706.

Hashimzade, N. AND S. OrTigueira (2005): "Endogenous Business Cycles With Frictional Labour Markets," Economic Journal, 115, 161-175, https://doi.org/10.1111/j.0013-0133.2005.00985.x.

Hodrick, R. J. (2020): “An Exploration of Trend-Cycle Decomposition Methodologies in Simulated Data,” NBER Working Paper 26750, https://doi.org/10.3386/w26750.

Hosios, A. J. (1990): “On The Efficiency of Matching and Related Models of Search and Unemployment," Review of Economic Studies, 57, 279-298, https://doi.org/10.2307/2297382. Ilut, C., M. Kehrig, AND M. Schneider (2018): "Slow to Hire, Quick to Fire: Employment Dynamics with Asymmetric Responses to News," Journal of Political Economy, 126, 2011-2071, https://doi.org/10.1086/699189.

JUNG, P. AND K. KUESTER (2011): “The (un)importance of unemployment fluctuations for the welfare cost of business cycles," Journal of Economic Dynamics and Control, 35, 1744-1768, https://doi.org/10.1016/j.jedc.2011.05.008. 
Jurado, K., S. C. Ludvigson, And S. NG (2015): “Measuring Uncertainty,” American Economic Review, 105, 1177-1216, https://www.doi.org/10.1257/aer.20131193.

Koop, G., M. H. Pesaran, And S. M. Potter (1996): "Impulse Response Analysis in Nonlinear Multivariate Models," Journal of Econometrics, 74, 119-147, https://doi.org/10.1016/0304-4076(95)01753-4.

Lepetit, A. (2020): “Asymmetric Unemployment Fluctuations and Monetary Policy Trade-Offs," Review of Economic Dynamics, 36, 29-45, https://doi.org/10.1016/j.red.2019.07.005.

LJUngQVist, L. And T. J. S ARgent (2017): “The Fundamental Surplus,” American Economic Review, 107, 2630-2665, https://doi.org/10.1257/aer.20150233.

LUCAS, JR, R. E. (1987): Models of Business Cycles, Oxford: Basil Blackwell. (2003): “Macroeconomic Priorities," American Economic Review, 93, 1-14, https://doi.org/10.1257/000282803321455133.

Ludvigson, S. C., S. MA, AND S. NG (2020): "Uncertainty and Business Cycles: Exogenous Impulse or Endogenous Response?” American Economic Journal: Marcoeconomics, forthcoming.

MendozA, E. G. (2010): “Sudden Stops, Financial Crises, and Leverage," American Economic Review, 100, 1941-1966, https://doi.org/10.1257/aer.100.5.1941.

Mercan, Y., B. Schoefer, And P. SedlaceK (2021): “A Congestion Theory of Unemployment Fluctuations," CEPR Discussion Paper DP15500.

MERZ, M. (1995): "Search in the labor market and the real business cycle," Journal of Monetary Economics, 36, 269-300, https://doi.org/10.1016/0304-3932(95)01216-8.

Mortensen, D. And E. NAgy PAL (2007): "More on Unemployment and Vacancy

Fluctuations," Review of Economic Dynamics, 10, 327-347, https://doi.org/10.1016/j.red.2007.01.004.

Petrongolo, B. And C. A. Piss ARIDes (2001): "Looking into the Black Box: A Survey of the Matching Function," Journal of Economic Literature, 39, 390-431, https://doi.org/10.1257/jel.39.2.390.

Petrosky-Nadeau, N. And E. WAsmer (2017): Labor, Credit, and Goods Markets: The macroeconomics of search and unemployment, Cambridge, MA, USA: MIT Press, 1st ed.

Petrosky-NADEAU, N. AND L. Zhang (2017): "Solving the Diamond-Mortensen-Pissarides model accurately," Quantitative Economics, 8, 611-650, https://doi.org/10.3982/QE452. - (2021): “Unemployment crises," Journal of Monetary Economics, 117, 335-353, https://doi.org/10.1016/j.jmoneco.2020.01.009.

Petrosky-Nadeau, N., L. Zhang, And L.-A. Kuehn (2018): "Endogenous Disasters," American Economic Review, 108, 2212-2245, https://doi.org/10.1257/aer.20130025.

PISSARIDES, C. A. (2000): Equilibrium Unemployment Theory, 2nd Edition, vol. 1 of MIT Press Books, The MIT Press. 
(2009): “The Unemployment Volatility Puzzle: Is Wage Stickiness the Answer?"

Econometrica, 77, 1339-1369, https://doi.org/10.3982/ECTA7562.

Pizzinelli, C., K. Theodoridis, And F. Zanetti (2020): "State Dependence in Labor

Market Fluctuations," International Economic Review, 61, 1027-1072,

https://doi.org/10.1111/iere.12448.

Plante, M., A. W. Richter, And N. A. Throckmorton (2018): “The Zero Lower Bound and Endogenous Uncertainty," Economic Journal, 128, 1730-1757, https://doi.org/10.1111/ecoj.12445.

Richter, A. W., N. A. Throckmorton, And T. B. Walker (2014): “Accuracy, Speed and Robustness of Policy Function Iteration," Computational Economics, 44, 445-476, https://doi.org/10.1007/s10614-013-9399-2.

Shimer, R. (2005): “The Cyclical Behavior of Equilibrium Unemployment and Vacancies," American Economic Review, 95, 25-49, https://doi.org/10.1257/0002828053828572.

Sims, C. A. (2002): "Solving Linear Rational Expectations Models," Computational Economics, 20, 1-20, https://doi.org/10.1023/A:1020517101123.

Stevens, M. (2007): "New Microfoundations For The Aggregate Matching Function," International Economic Review, 48, 847-868, https://doi.org/10.1111/j.1468-2354.2007.00447.x.

StRAub, L. AND R. UlBRICHT (2015): “Endogenous Uncertainty and Credit Crunches," Toulouse School of Economics Working Paper 15-604.

VAn Nieuwerburgh, S. And L. VeldKamp (2006): “Learning Asymmetries in Real Business Cycles," Journal of Monetary Economics, 53, 753-772, https://doi.org/10.1016/j.jmoneco.2005.02.003.

\section{A Data Sources and Transformations}

We use the following time-series from 1955-2019 provided by Haver Analytics:

1. Labor Productivity, Non-farm Business Sector, All Persons, Seasonally Adjusted, Quarterly, 2012=100 (LXNFS@USECON)

2. Labor Share, Non-farm Business Sector, All Persons, Seasonally Adjusted, Quarterly, Percent (LXNFBL@USECON)

3. Job Openings, Job Openings and Labor Turnover Survey, Seasonally Adjusted, Monthly, Thousands (LJJTLA@USECON)

\section{Unemployed, 16 Years \& Over}

Seasonally Adjusted, Monthly, Thousands (LTU@USECON) 


\section{Civilian Labor Force: 16 yr \& Over}

Seasonally Adjusted, Monthly, Thousands (LF@USECON)

\section{Civilians Unemployed for Less Than 5 Weeks}

Seasonally Adjusted, Monthly, Thousands (LU0@USECON)

We also used the following data from other sources:

1. Help Wanted Advertising Index (HWI), based on Barnichon (2010) and in units of the labor force. The series corrects for online advertising and is available on the author's website.

2. Real Uncertainty (U), 1-quarter horizon, based on Ludvigson et al. (2020). The series is available on Ludvigson's website. The monthly series is averaged to a quarterly frequency.

We applied the following transformations to the above data sources:

1. Unemployment Rate: $U_{t}=100\left(L T U_{t} / L F_{t}\right)$.

2. Vacancy Rate: $H W I$ from 1954M1-2000M12 and LJJTLA/LF from 2001M1-2019M12.

3. Short-term Unemployed $\left(U^{s}\right)$ : The redesign of the Current Population Survey (CPS) in 1994 reduced $u_{t}^{s}$. To correct for this bias, we follow Elsby et al. (2009) and scale $u_{t}^{s}$ by the time average of the ratio of $u_{t}^{s} / u_{t}$ for the first and fifth rotations groups to $u_{t}^{s} / u_{t}$ across all rotation groups. Using IPUMS-CPS data, we extract EMPSTAT ("Employment Status"), DURUNEMP ("Continuous weeks unemployed") and MISH ("Month in sample, household level”). Unemployed persons have EMPSTAT equal to 20, 21, or 22. Short-term unemployed are persons who are unemployed and have DURUNEMP equal to 4 or less. Incoming rotation groups have MISH equal to 1 or 5 . Using the final weights, WTFINL, we calculate unemployment rates conditional on the appropriate values of MISH and DURUNEMP. We then apply the X-12 seasonal adjustment function in STATA to the time series for the ratio. Finally, we take an average of the seasonally adjusted series from 1994-2019. This process yields an average of 1.1725 , so $U^{s}$ equals $L U 0$ prior to 1994 and $1.1725 \times L U 0$ after 1994 .

4. Job Finding Rate: $f_{t}=1-\left(L T U_{t}-U_{t}^{s}\right) / L T U_{t-1}$.

5. Real Wage: $w_{t}=L X N F B L_{t} \times L X N F S_{t}$

6. Wage Elasticity: Slope coefficient from regressing $w_{t}$ on an intercept and $L X N F S_{t}$.

7. Job Separation Rate: $s_{t}=1-\exp \left(-\tilde{s}_{t}\right)$, where $\tilde{s}_{t}$ satisfies

$$
L T U_{t+1}=\frac{\left(1-\exp \left(-\tilde{f}_{t}-\tilde{s}_{t}\right)\right) \tilde{s}_{t} L F_{t}}{\tilde{f}_{t}+\tilde{s}_{t}}+\exp \left(-\tilde{f}_{t}-\tilde{s}_{t}\right) L T U_{t}, \quad \tilde{f}_{t}=-\log \left(1-f_{t}\right) .
$$

All monthly time series are averaged to a quarterly frequency. The data is detrended using a Hamilton filter with an 8 quarter window. All empirical targets are computed using quarterly data. 


\section{B Solution Method}

Our baseline model only includes labor productivity shocks. This section describes the more general problem that also includes job separation rate shocks because it is considered in Appendix D.

The nonlinear equilibrium system can be compactly written as

$$
E_{t}\left[g\left(\mathbf{x}_{t+1}, \mathbf{x}_{t}, \mathcal{E}_{t+1}\right) \mid \mathbf{z}_{t}, \mathcal{P}\right]=0
$$

where $g$ is a vector-valued function, $\mathbf{x}_{t}$ is a vector of variables, $\mathcal{E}_{t}=\left\{\varepsilon_{a, t}, \varepsilon_{s, t}\right\}$ is a vector of shocks, $\mathbf{z}_{t}$ is a vector of endogenous and exogenous state variables, and $\mathcal{P}$ is a vector of model parameters.

The bounds on the state variables, $a_{t}, s_{t}$, and $n_{t-1}$ are set to [0.925, 1.075], [0.024, 0.041], and $[0.85,0.995]$, which contains at least $99 \%$ of the ergodic distribution. We discretize each state into 11 evenly-spaced points. The product of the points in each dimension, $D$, is the total nodes in the state space $(D=1,331)$. The realization of $\mathbf{z}_{t}$ on node $d$ is denoted $\mathbf{z}_{t}(d)$. We discretize the exogenous states separately from the shocks, $\varepsilon_{a, t+1}$ and $\varepsilon_{s, t+1}$, which are discretized according to Gauss-Hermite quadrature for standard-normal i.i.d. random variables using 7 points (i.e., $\pm 2.65 S D)$. The Gauss-Hermite method provides integration weights, $\phi(m)$, for $m \in\{1, \ldots, M\}$.

Since vacancies $v_{t} \geq 0$, we introduce an auxiliary variable, $\mu_{t}$, such that $v_{t}=\max \left\{0, \mu_{t}\right\}^{2}$ and $\lambda_{0, t}=\max \left\{0,-\mu_{t}\right\}^{2}$, where $\lambda_{0, t}$ is the Lagrange multiplier on the non-negativity constraint. If $\mu_{t} \geq 0$, then $v_{t}=\mu_{t}^{2}$ and $\lambda_{0, t}=0$. When $\mu_{t}<0$, the constraint is binding, $v_{t}=0$, and $\lambda_{0, t}=\mu_{t}^{2}$. Therefore, the constraint on $v_{t}$ is transformed into a pair of equalities (Garcia and Zangwill, 1981).

The following steps outline our nonlinear policy function iteration algorithm:

1. Use Sims's (2002) gensys algorithm to solve the log-linear model. Then map the solution for the policy functions to the discretized state space. This provides an initial conjecture.

2. On iteration $j \in\{1,2, \ldots\}$ and each node $d \in\{1, \ldots, D\}$, use Chris Sims's csolve to find $\mu_{t}(d)$ to satisfy $E\left[g(\cdot) \mid \mathbf{z}_{t}(d), \mathcal{P}\right] \approx 0$. Guess $\mu_{t}(d)=\mu_{j-1}(d)$. Then apply the following:

(a) Solve for all variables dated at time $t$, given $\mu_{t}(d)$ and $\mathbf{z}_{t}(d)$.

(b) Linearly interpolate the policy function, $\mu_{j-1}$, at the updated state variables, $\mathbf{z}_{t+1}(m)$, to obtain $\mu_{t+1}(m)$ on every integration node, $m \in\{1, \ldots, M\}$.

(c) Given $\left\{\mu_{t+1}(m)\right\}_{m=1}^{M}$, solve for the other elements of $\mathbf{x}_{t+1}(m)$ and compute

$$
E\left[g\left(\mathbf{x}_{t+1}, \mathbf{x}_{t}(d), \mathcal{E}_{t+1}\right) \mid \mathbf{z}_{t}(d), \mathcal{P}\right] \approx \sum_{m=1}^{M} \phi(m) g\left(\mathbf{x}_{t+1}(m), \mathbf{x}_{t}(d), \mathcal{E}_{t+1}(m)\right)
$$

Set $\mu_{j}(d)=\mu_{t}(d)$ when csolve converges.

3. Repeat step 2 until maxdist m $_{j}<10^{-6}$, where $\operatorname{maxdist}_{j} \equiv \max \left\{\left|\mu_{j}-\mu_{j-1}\right|\right\}$. When that criterion is satisfied, the algorithm has converged to an approximate nonlinear solution. 


\section{NASh BARGaining}

An alternative to the linear wage rule (10) in the main paper is to set wages using the Nash bargaining protocol. This section analytically and numerically shows that Nash bargaining only has a small effect on the nonlinear dynamics of the model, leaving our qualitative insights unchanged.

Under Nash bargaining, the wage is given by

$$
w_{t}=\eta\left(a_{t}+\kappa(1-\chi \bar{s}) E_{t}\left[x_{t+1} \theta_{t+1}\right]\right)+(1-\eta) b .
$$

Combine (19) with the vacancy posting condition and impose risk neutrality to obtain

$$
\kappa / q_{t}=(1-\eta)\left(a_{t}-b\right)+\beta E_{t}\left[x_{t+1}\left((1-\bar{s}) \kappa / q_{t+1}-\eta \kappa(1-\chi \bar{s}) \theta_{t+1}\right)\right] .
$$

Since both the CD and DRW matching functions imply that $\theta_{t+1}$ is generally a nonlinear function of $\kappa / q_{t+1}$, (20) shows that the key effect of Nash bargaining is to make the marginal cost of vacancy creation a nonlinear function of productivity. Importantly, the extent to which this nonlinearity matters is governed by the size of the bargaining parameter $\eta$. To solve (20) in closed form, consider the DRW matching function with $\iota=1$, so $q_{t}=1 /\left(1+\theta_{t}\right)$ and $\theta_{t}=1 / q_{t}-1$. Then (20) becomes

$$
\kappa / q_{t}=(1-\eta)\left(a_{t}-b\right)+\beta E_{t}\left[(1-\bar{s}-\eta(1-\chi \bar{s})) \kappa / q_{t+1}+\eta \kappa(1-\chi \bar{s})\right] .
$$

We can once again guess and verify that (21) has a solution of the form,

$$
\kappa / q_{t}=\delta_{0}+\delta_{1}\left(a_{t}-\bar{a}\right)
$$

where

$$
\delta_{0}=\frac{(1-\eta)(\bar{a}-b)+\beta \eta \kappa(1-\chi \bar{s})}{1-\beta\left(1-\bar{s}-\eta\left(1-\chi^{\bar{s}}\right)\right)}, \quad \delta_{1}=\frac{1-\eta}{1-\beta(1-\bar{s}-\eta(1-\chi \bar{s})) \rho_{a}} .
$$

In this case, the marginal cost of vacancy creation is linear in productivity. Consistent with the general case where $\iota \neq 1$, the extent to which Nash bargaining matters depends on the size of $\eta$.

As in the main paper, we estimate the model with Nash bargaining using the DRW matching function. Table 3 shows the parameter estimates and empirical targets. Importantly, the estimated value of $\eta=0.115$ is small, suggesting that Nash bargaining will have a minor effect on the model.

We quantify this intuition by comparing Table 2 in the main paper with Table 4 (based on the parameter estimates from Table 3). Focusing on the higher-order moments, we see Nash bargaining has a relatively small effect compared to the matching function and the law of motion for unemployment. For example, in the baseline estimated model, Nash bargaining increases the skewness of unemployment by $4 \%$, from 1.91 to 1.98 . Nash bargaining is more powerful under the CD matching function, increasing the skewness of unemployment by $29 \%$ and doubling the skewness of the job finding rate. However, these effects are still much smaller than switching to the DRW 


\begin{tabular}{lcclcc}
\hline Model Parameter & & Value & Empirical Target & Data & Model \\
\hline Intra-Period Search Duration & $\chi$ & 0.5288 & Average Unemployment Rate & 5.89 & 5.89 \\
Vacancy Posting Cost & $\kappa$ & 0.2025 & Average Job-Finding Rate & 42.14 & 42.14 \\
Job Separation Rate & $\bar{s}$ & 0.0327 & Average Job Separation Rate & 3.27 & 3.27 \\
Disagreement Payoff & $b$ & 0.9248 & Unemployment Standard Deviation & 23.66 & 23.66 \\
Matching Elasticity & $\bar{\epsilon}_{m, u^{s}}$ & 0.5868 & Vacancy Standard Deviation & 21.69 & 21.69 \\
Bargaining Weight & $\eta$ & 0.1146 & Wage-Labor Productivity Elasticity & 0.59 & 0.59 \\
Productivity Persistence & $\rho_{a}$ & 0.9537 & Labor Prod. Autocorrelation & 0.89 & 0.89 \\
Shock Standard Deviation & $\sigma_{a}$ & 0.0083 & Labor Prod. Standard Deviation & 2.61 & 2.61 \\
\hline
\end{tabular}

Table 3: Estimated parameter values with the DRW matching function and Nash bargaining.

\begin{tabular}{|c|c|c|c|c|c|c|c|c|}
\hline \multicolumn{2}{|c|}{ Nash Bargaining Model } & \multirow[b]{2}{*}{ SE } & \multicolumn{2}{|c|}{ DRW } & \multicolumn{2}{|c|}{$\mathrm{CD}$} & \multicolumn{2}{|c|}{ Linear } \\
\hline Moment & Data & & 1 & 2 & 1 & 2 & 3 & 4 \\
\hline$S D(u)$ & 23.66 & 2.51 & 23.66 & 17.22 & 18.21 & 16.00 & 16.63 & 16.06 \\
\hline$S D(v)$ & 21.69 & 1.51 & 21.69 & 22.58 & 21.50 & 21.74 & 20.29 & 21.02 \\
\hline$S D(f)$ & 14.96 & 1.47 & 15.74 & 15.66 & 14.02 & 14.00 & 13.35 & 13.35 \\
\hline $\operatorname{Skew}(u)$ & 1.10 & 0.35 & 1.98 & 0.80 & 1.06 & 0.28 & 0.65 & 0.00 \\
\hline $\operatorname{Skew}(v)$ & -0.02 & 0.35 & -0.23 & -0.40 & -0.15 & -0.34 & 0.26 & 0.00 \\
\hline $\operatorname{Skew}(f)$ & -0.60 & 0.45 & -0.85 & -0.83 & -0.31 & -0.29 & -0.01 & 0.00 \\
\hline Slope $(w, a)$ & 0.59 & 0.08 & 0.59 & 0.59 & 0.58 & 0.58 & 1.07 & 0.85 \\
\hline $\operatorname{Corr}(u, v)$ & -0.74 & 0.05 & -0.85 & -0.95 & -0.92 & -0.95 & -0.91 & -0.95 \\
\hline$S D\left(U_{u}\right)$ & 6.49 & 0.59 & 6.01 & 4.33 & 3.39 & 1.62 & 3.23 & 0.00 \\
\hline
\end{tabular}

Table 4: Data and simulated moments. Models: (1) All nonlinear; (2) All nonlinear except linear law of motion; (3) All linear except nonlinear law of motion; (4) All linear. Bolded values indicate targeted moments.

matching function, which almost doubles the skewness of unemployment and triples the skewness of the job finding rate. Furthermore, the $\mathrm{CD}$ matching function remains a weak source of nonlinearity compared to the law of motion for unemployment. Comparing columns CD-1 and CD-2 shows the law of motion is responsible for $74 \%$ of the skewness in unemployment under Nash bargaining.

\section{Job Separation Rate Shocks}

This section introduces job separation rate shocks to our baseline model, given their recent emphasis in the literature. Following Coles and Kelishomi (2018) and Mercan et al. (2021), there is positive correlation between productivity and the job separation rate. The processes evolve according to

$$
\begin{aligned}
& a_{t}=\bar{a}+\rho_{a}\left(a_{t-1}-\bar{a}\right)+\rho_{a s} \sigma_{s} \varepsilon_{s, t}+\sigma_{a} \varepsilon_{a, t}, 0 \leq \rho_{a}<1, \varepsilon_{a} \sim \mathbb{N}(0,1), \\
& s_{t}=\bar{s}+\rho_{s}\left(s_{t-1}-\bar{s}\right)+\rho_{a s} \sigma_{a} \varepsilon_{a, t}+\sigma_{s} \varepsilon_{s, t}, 0 \leq \rho_{s}<1, \varepsilon_{s} \sim \mathbb{N}(0,1),
\end{aligned}
$$




\begin{tabular}{lcclcc}
\hline Model Parameter & & Value & Empirical Target & Data & Model \\
\hline Intra-Period Search Duration & $\chi$ & 0.5159 & Average Unemployment Rate & 5.89 & 5.89 \\
Vacancy Posting Cost & $\kappa$ & 0.0732 & Average Job-Finding Rate & 42.14 & 42.14 \\
Job Separation Rate & $\bar{s}$ & 0.0327 & Average Job Separation Rate & 3.27 & 3.27 \\
Disagreement Payoff & $b$ & 0.9419 & Unemployment Standard Deviation & 23.66 & 23.66 \\
Matching Elasticity & $\bar{\epsilon}_{m, u^{s}}$ & 0.6713 & Vacancy Standard Deviation & 21.69 & 21.69 \\
Bargaining Weight & $\eta$ & 0.5744 & Wage-Labor Productivity Elasticity & 0.59 & 0.59 \\
Productivity Persistence & $\rho_{a}$ & 0.9537 & Labor Prod. Autocorrelation & 0.89 & 0.89 \\
Shock Standard Deviation & $\sigma_{a}$ & 0.0083 & Labor Prod. Standard Deviation & 2.61 & 2.61 \\
Separation Rate Persistence & $\rho_{s}$ & 0.8985 & Separation Rate Autocorrelation & 0.79 & 0.79 \\
Shock Standard Deviation & $\sigma_{s}$ & 0.0012 & Separation Rate Standard Deviation & 8.97 & 8.97 \\
Shock Cross-Correlation & $\rho_{a s}$ & -0.0814 & Prod. and Sep. Rate Correlation & -0.47 & -0.47 \\
\hline
\end{tabular}

Table 5: Estimated parameter values with the DRW matching function and correlated shocks.

\begin{tabular}{|c|c|c|c|c|c|c|c|c|}
\hline \multicolumn{2}{|c|}{ Correlated Shocks Model } & \multirow[b]{2}{*}{ SE } & \multicolumn{2}{|c|}{ DRW } & \multicolumn{2}{|c|}{$\mathrm{CD}$} & \multicolumn{2}{|c|}{ Linear } \\
\hline Moment & Data & & 1 & 2 & 1 & 2 & 3 & 4 \\
\hline$S D(u)$ & 23.66 & 2.51 & 23.66 & 19.11 & 19.89 & 18.11 & 19.12 & 18.81 \\
\hline$S D(v)$ & 21.69 & 1.51 & 21.69 & 22.35 & 21.17 & 21.37 & 20.17 & 20.72 \\
\hline$S D(f)$ & 14.96 & 1.47 & 13.04 & 12.85 & 11.40 & 11.31 & 10.95 & 10.94 \\
\hline $\operatorname{Skew}(u)$ & 1.10 & 0.35 & 1.41 & 0.46 & 0.75 & 0.16 & 0.53 & 0.00 \\
\hline $\operatorname{Skew}(v)$ & -0.02 & 0.35 & -0.16 & -0.27 & -0.07 & -0.18 & 0.17 & 0.00 \\
\hline $\operatorname{Skew}(f)$ & -0.60 & 0.45 & -0.80 & -0.75 & -0.27 & -0.26 & -0.02 & 0.00 \\
\hline Slope $(w, a)$ & 0.59 & 0.08 & 0.59 & 0.59 & 0.59 & 0.59 & 0.59 & 0.59 \\
\hline $\operatorname{Corr}(u, v)$ & -0.74 & 0.05 & -0.73 & -0.75 & -0.73 & -0.72 & -0.70 & -0.73 \\
\hline$S D\left(U_{u}\right)$ & 6.49 & 0.59 & 4.60 & 2.64 & 2.48 & 0.89 & 2.25 & 0.00 \\
\hline
\end{tabular}

Table 6: Data and simulated moments. Models: (1) All nonlinear; (2) All nonlinear except linear law of motion; (3) All linear except nonlinear law of motion; (4) All linear. Bolded values indicate targeted moments.

where $\rho_{a s}$ governs the correlation between the shocks. The vacancy creation condition becomes

$$
\frac{\kappa-\lambda_{v, t}}{q_{t}}=a_{t}-w_{t}+E_{t}\left[x_{t+1}\left(1-s_{t+1}\right) \frac{\kappa-\lambda_{v, t+1}}{q_{t+1}}\right] .
$$

Unfortunately, this model does not have a closed-form solution, even under risk-neutrality. However, it is clear from (22) that the marginal cost of vacancy creation becomes a nonlinear function of both shocks, whereas it was a linear function of only labor productivity in our baseline model. Thus, job separation rate shocks add a potentially important source of asymmetry to the labor market, in addition to the asymmetry from the matching function and law of motion for unemployment.

Table 5 shows the parameter estimates for the model with a DRW matching function and correlated shocks. Once again, they are perfectly identified. The estimated cross-correlation between the two shocks is negative, consistent with the literature. Most of the labor market parameters are 
similar to the model without job separation shocks. The one notable exception is the steady-state matching elasticity, $\bar{\epsilon}_{m, u^{s}}=0.671$, which is up from 0.592 in our baseline model. Our analytical results indicate that this will decrease the nonlinearities generated by the DRW matching function.

Table 6 shows the same moments and specifications as Table 2 for the model with correlated shocks. The qualitative results are consistent with our baseline model. The DRW matching function alone continues to explain a large portion of the nonlinearities, while removing time-variation in the matching elasticity significantly reduces the nonlinearities. However, job separation rate shocks alter the model's performance in a few ways. First, with the DRW matching function the skewness of unemployment (1.41) is closer to the data (1.14), since the model can match our empirical targets with a higher matching elasticity. Second, job separation rate shocks help both models match the correlation between unemployment and vacancies (i.e., Beveridge curve). Third, with the $\mathrm{CD}$ matching function nonlinearity in the marginal cost of vacancy creation generates more skewness in the job finding rate $(-0.27)$. However, it still below the skewness in the data $(-0.61)$.

\section{E Cobb-Douglas Parameter Estimates}

In the main paper, we estimate the model using the DRW matching function and then compare various model specifications conditional on those parameter estimates. This section shows our qualitative results are robust to alternatively estimating the model with the CD matching function.

Table 7 shows the parameter estimates, which are once again perfectly identified by our empirical targets. The one notable change is that the steady-state matching elasticity, $\bar{\epsilon}_{m, u^{s}}=\alpha$, declines from 0.592 to 0.505 . As a result, the elasticity of substitution, $\sigma=1 /(1+\iota)$, under the DRW matching function decreases from 0.608 to 0.548 (equivalently, $\iota$ increases from 0.645 to 0.826 ).

Table 8 reports the moments for the same specifications as Table 2. The moments under the CD matching function (column CD-1) are similar to the moments under the DRW parameter estimates. The differences are larger for the DRW matching function (column DRW-1). The lower estimate of the elasticity of substitution increases the standard deviation of the matching elasticity from 0.05 to 0.09 . This causes the skewness of unemployment to rise from 1.91 to 2.48. Comparing columns CD-1 and DRW-1 isolates the effects of the procyclical matching elasticity. Using the CD matching function, which removes time-variation in the matching elasticity, reduces the skewness in unemployment by $62 \%$, the skewness in the job finding rate by $99 \%$, and the volatility in unemployment uncertainty by $57 \%$. These percentages are qualitatively identical to the values in the main paper.

\section{F ECONOMIC EFFICIENCY}

It is well known that the equilibrium in a broad class of models with search and matching frictions is generally inefficient (Hosios, 1990). The inefficiencies stem from two externalities generated 


\begin{tabular}{lcclcc}
\hline Model Parameter & & Value & Empirical Target & Data & Model \\
\hline Intra-Period Search Duration & $\chi$ & 0.5396 & Average Unemployment Rate & 5.89 & 5.89 \\
Vacancy Posting Cost & $\kappa$ & 0.3580 & Average Job-Finding Rate & 42.14 & 42.14 \\
Job Separation Rate & $\bar{s}$ & 0.0327 & Average Job Separation Rate & 3.27 & 3.27 \\
Disagreement Payoff & $b$ & 0.9328 & Unemployment Standard Deviation & 23.66 & 23.66 \\
Matching Elasticity & $\bar{\epsilon}_{m, u^{s}}$ & 0.5047 & Vacancy Standard Deviation & 21.69 & 21.69 \\
Bargaining Weight & $\eta$ & 0.5720 & Wage-Labor Productivity Elasticity & 0.59 & 0.59 \\
Productivity Persistence & $\rho_{a}$ & 0.9537 & Labor Prod. Autocorrelation & 0.89 & 0.89 \\
Shock Standard Deviation & $\sigma_{a}$ & 0.0083 & Labor Prod. Standard Deviation & 2.61 & 2.61 \\
\hline
\end{tabular}

Table 7: Estimated parameter values with the CD matching function.

\begin{tabular}{|c|c|c|c|c|c|c|c|c|}
\hline \multicolumn{2}{|c|}{ CD Parameter Estimates } & \multirow[b]{2}{*}{ SE } & \multicolumn{2}{|c|}{ DRW } & \multicolumn{2}{|c|}{$\mathrm{CD}$} & \multicolumn{2}{|c|}{ Linear } \\
\hline Moment & Data & & 1 & 2 & 1 & 2 & 3 & 4 \\
\hline$S D(u)$ & 23.66 & 2.51 & 41.42 & 23.35 & 23.66 & 20.48 & 24.24 & 22.23 \\
\hline$S D(v)$ & 21.69 & 1.51 & 23.89 & 26.81 & 21.69 & 21.76 & 20.17 & 21.62 \\
\hline$S D(f)$ & 14.96 & 1.47 & 23.72 & 24.08 & 18.49 & 18.32 & 18.41 & 18.36 \\
\hline $\operatorname{Skew}(u)$ & 1.10 & 0.35 & 2.48 & 0.78 & 0.94 & -0.02 & 1.02 & 0.00 \\
\hline $\operatorname{Skew}(v)$ & -0.02 & 0.35 & -0.43 & -0.62 & -0.03 & -0.32 & 0.39 & 0.00 \\
\hline $\operatorname{Skew}(f)$ & -0.60 & 0.45 & -0.82 & -0.81 & -0.01 & 0.02 & -0.05 & 0.00 \\
\hline Slope $(w, a)$ & 0.59 & 0.08 & 0.59 & 0.59 & 0.59 & 0.59 & 0.59 & 0.59 \\
\hline $\operatorname{Corr}(u, v)$ & -0.74 & 0.05 & -0.76 & -0.94 & -0.90 & -0.92 & -0.80 & -0.93 \\
\hline$S D\left(U_{u}\right)$ & 6.49 & 0.59 & 5.26 & 4.17 & 2.25 & 0.10 & 4.61 & 0.00 \\
\hline
\end{tabular}

Table 8: Data and simulated moments. Models: (1) All nonlinear; (2) All nonlinear except linear law of motion; (3) All linear except nonlinear law of motion; (4) All linear. Bolded values indicate targeted moments.

by firms' vacancy creation decisions. First, when a firm posts an additional vacancy, it imposes a positive externality on unemployed searching workers who face a higher job finding rate. Second, the same vacancy posting imposes a negative externality on other firms who face lower job filling rates and higher marginal costs of vacancy creation today and in the future. To see how the matching function affects these externalities and hence efficiency, we compare the equilibrium to the solution of the planning problem in which both externalities are internalized. The planner solves:

$$
W_{t}=\max _{c_{t}, n_{t}, v_{t}} c_{t}^{1-\gamma} /(1-\gamma)+\beta E_{t} W_{t+1}
$$

subject to

$$
\begin{gathered}
c_{t}+\kappa v_{t}=a_{t} n_{t}+b\left(1-n_{t}\right), \\
u_{t}^{s}=1-n_{t-1}+\chi \bar{s} n_{t-1}, \\
n_{t}=(1-\bar{s}) n_{t-1}+\mathcal{M}\left(u_{t}^{s}, v_{t}\right),
\end{gathered}
$$


where $v_{t} \geq 0$. The optimality conditions imply

$$
\frac{\kappa-\lambda_{v, t}}{\mathcal{M}_{2}\left(u_{t}^{s}, v_{t}\right)}=a_{t}-b+E_{t}\left[x_{t+1} \frac{\kappa-\lambda_{v, t+1}}{\mathcal{M}_{2}\left(u_{t+1}^{s}, v_{t+1}\right)}\left(1-\bar{s}-\mathcal{M}_{1}\left(u_{t+1}^{s}, v_{t+1}\right)(1-\chi \bar{s})\right)\right],
$$

which determines the socially optimal level of vacancies by setting the social marginal cost (SMC) of vacancy creation equal to the social marginal benefit (SMB). The gaps between the SMC and SMB and the private marginal cost (PMC) and private marginal benefit (PMB) capture the externalities and inefficiencies of the equilibrium, which motivate taxes and subsides that restore efficiency.

To characterize these gaps, we follow the public finance literature and solve for the wedgesstate-dependent, linear taxes or subsidies - that equate the two solutions. Formally, we ask what subsidies or taxes on a firm's private vacancy creation and employment choices would incentivize it to choose the socially optimal level of vacancy postings? Let $\tau_{v, t}$ denote a subsidy on vacancy creation, $v_{t}$, and $\tau_{n, t}$ a subsidy on a firm's current payroll, $n_{t-1}$, such that a firm's flow profits are $\left(a_{t}-w_{t}\right) n_{t}-\left(1-\tau_{v, t}\right) \kappa v_{t}+\tau_{n, t} n_{t-1}$. Taking the wedges as given, a representative firm solves:

$$
V_{t}=\max _{n_{t}, v_{t}}\left(a_{t}-w_{t}\right) n_{t}-\left(1-\tau_{v, t}\right) \kappa v_{t}+\tau_{n, t} n_{t-1}+E_{t}\left[x_{t+1} V_{t+1}\right]
$$

subject to

$$
\begin{gathered}
n_{t}=(1-\bar{s}) n_{t-1}+q_{t} v_{t}, \\
\left(1-\tau_{v, t}\right) v_{t} \geq 0
\end{gathered}
$$

The optimality conditions imply

$$
\frac{\kappa-\lambda_{v, t}}{q_{t}}=\frac{1}{1-\tau_{v, t}}\left(a_{t}-w_{t}\right)+E_{t}\left[x_{t+1} \frac{1-\tau_{v, t+1}}{1-\tau_{v, t}}\left(\frac{\tau_{n, t+1}}{1-\tau_{v, t+1}}+(1-\bar{s}) \frac{\kappa-\lambda_{v, t+1}}{q_{t+1}}\right)\right] .
$$

Impose the linear wage rule in (10) to obtain

$$
\frac{\kappa-\lambda_{v, t}}{q_{t}}=\frac{1-\eta}{1-\tau_{v, t}}\left(a_{t}-b\right)+E_{t}\left[x_{t+1} \frac{\kappa-\lambda_{v, t+1}}{q_{t+1}} \frac{1-\tau_{v, t+1}}{1-\tau_{v, t}}\left(1-\bar{s}+\frac{\tau_{n, t+1}}{1-\tau_{v, t+1}} \frac{q_{t+1}}{\kappa-\lambda_{v, t+1}}\right)\right] .
$$

Therefore, the following restrictions

$$
\begin{aligned}
\frac{1-\eta}{1-\tau_{v, t}} & =\frac{\mathcal{M}_{2}\left(u_{t}^{s}, v_{t}\right)}{q_{t}} \\
\frac{\tau_{n, t+1}}{1-\tau_{v, t+1}} \frac{q_{t+1}}{\kappa-\lambda_{v, t+1}} & =-\mathcal{M}_{1}\left(u_{t+1}^{s}, v_{t+1}\right)(1-\chi \bar{s})
\end{aligned}
$$

ensure that the equilibrium vacancy posting decision is the same as the social optimum. Thus,

$$
\tau_{v, t}=1-\frac{1-\eta}{1-\epsilon_{m_{t}, u_{t}^{s}}}, \quad \tau_{n, t}=\frac{\epsilon_{m_{t}, u_{t}^{s}}}{1-\epsilon_{m_{t}, u_{t}^{s}}}(1-\eta)\left(\kappa-\lambda_{v, t}\right) \theta_{t}(1-\chi \bar{s}) .
$$


The expression for $\tau_{v, t}$ shows the vacancy subsidy balances both externalities. Note that $1-\eta$ is the ratio of the period- $t \mathrm{PMB},(1-\eta)\left(a_{t}-b\right)$, to the period- $t \mathrm{SMB}, a_{t}-b$. The elasticity $\epsilon_{m_{t}, v_{t}}=$ $1-\epsilon_{m_{t}, u_{t}^{s}}$ is the ratio of the PMC to the SMC, $\epsilon_{m_{t}, v_{t}}=\frac{\left(\kappa-\lambda_{v, t}\right) / q_{t}}{\left(\kappa-\lambda_{v, t}\right) / \mathcal{M}_{2}\left(u_{t}^{s}, v_{t}\right)}$. The sign of the wedge depends on which ratio is larger. There is a vacancy tax $\tau_{v, t}<0$ when $\eta<1-\epsilon_{m_{t}, v_{t}}=\epsilon_{m_{t}, u_{t}^{s}}$, so the marginal cost gap is smaller than the marginal benefit gap. This condition, which is satisfied under our baseline calibration, indicates there is inefficiently high private vacancy creation and that the negative externality on firms dominates the positive externality on workers. Crucially, the size of this externality is fixed under a CD matching function because $\epsilon_{m_{t}, u_{t}^{s}}$ is a constant. However, under a DRW matching function, $\epsilon_{m_{t}, u_{t}^{s}}$ is procyclical. Therefore, the externality is countercyclical and recessions are periods when the gap between private and socially optimal vacancy creation is large.

The expression for $\tau_{n, t}<0$ shows that a payroll tax is required for efficiency. This tax accounts for the gap between the period- $t+1 \mathrm{SMB}$ and PMB (the expectation terms). Intuitively, private vacancy creation boosts employment today, which lowers $u_{t+1}^{s}$ and hence raises the marginal cost of vacancy creation in the future. A payroll tax is necessary to limit private vacancy creation in period $t$, undoing the negative externality. Contrary to $\tau_{v, t}$, the procyclicality of labor market tightness implies that the payroll tax is time-varying under both the CD and DRW matching functions.
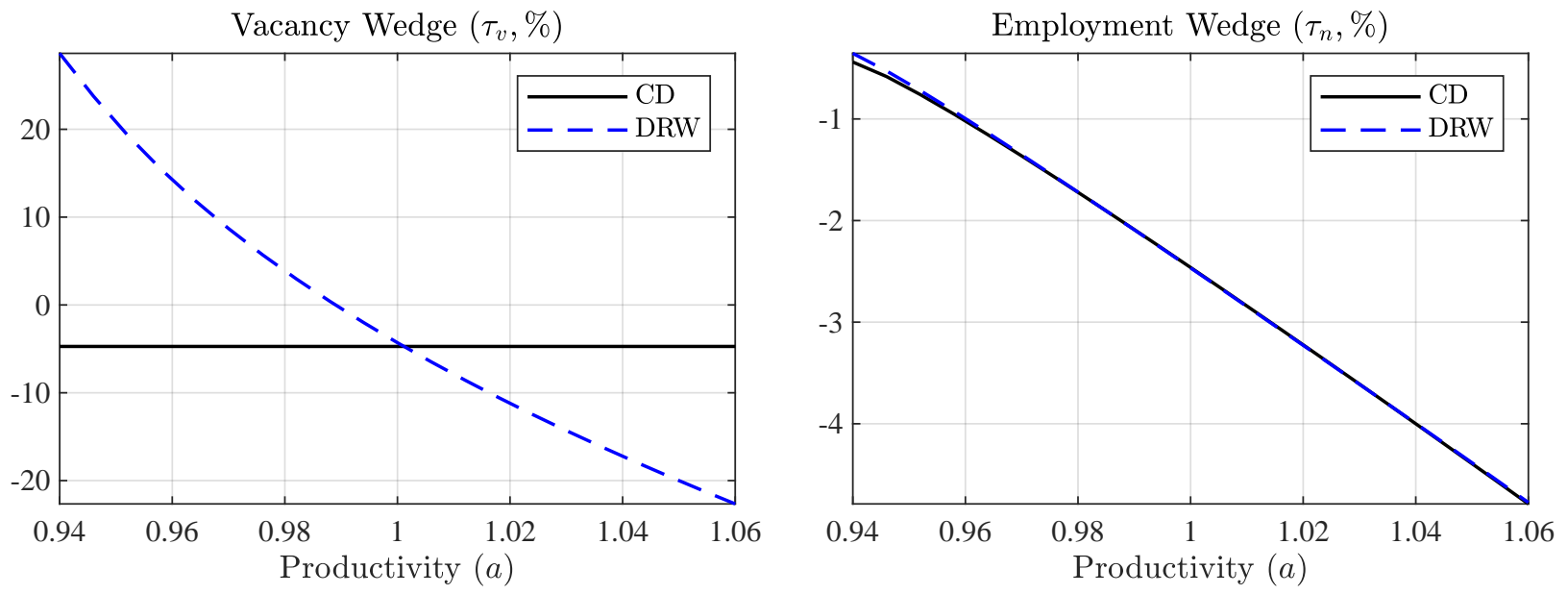

Figure 3: Vacancy and employment wedges that restore economic efficiency.

To illustrate these dynamics, Figure 3 plots the vacancy and employment wedges as a function of productivity. Under the CD matching function, it is optimal to issue a vacancy tax, but it is independent of the state of the economy. This suggests it is optimal to apply the same tax in recessions and booms. In contrast, the DRW matching function implies a quantitatively significant countercyclical vacancy subsidy, suggesting it is optimal to provide a large subsidy in recessions and impose a tax in a booms. The employment wedge, on the other hand, is similar across the two matching functions since variation in the DRW matching elasticity is offset by movements in tightness, $\theta_{t}$. 